\title{
Flexural toughness and calculation model of super-fine stainless wire reinforced reactive powder concrete
}

\author{
Sufen Dong ${ }^{1}$, Daocheng Zhou ${ }^{2}$, Ashraf Ashour ${ }^{3}$, Baoguo $\mathrm{Han}^{4,}{ }^{4}$, Jinping $\mathrm{Ou}^{4}$ \\ ${ }^{1}$ School of Material Science and Engineering, Dalian University of Technology, Dalian, 116024 China \\ ${ }^{2}$ Deepwater Engineering Research Center, Dalian University of Technology, Dalian, 116024 China \\ ${ }^{3}$ Faculty of Engineering \& Informatics, University of Bradford, Bradford, BD7 1DP, UK \\ ${ }^{4}$ School of Civil Engineering, Dalian University of Technology, Dalian, 116024 China \\ * Corresponding author: hithanbaoguo@163.com, hanbaoguo@dlut.edu.cn
}

\begin{abstract}
:
As a type of excellent reinforcing filler, super-fine stainless wire (SSW) can form widely distributed network in reactive powder concrete (RPC) to transfer crack tip stresses as well as inhibit the initiation and propagation of cracks, leading to significant improvement of flexural toughness of RPC. In this paper, the flexural toughness of RPC beams and plates reinforced with $1 \%$ and $1.5 \%$ by vol. of SSWs was investigated, and its calculation model was established according to the composite material theory. Experimental results showed that the flexural toughness of unnotched beams fabricated with RPC containing $1.5 \%$ SSWs is $146.5 \%$ higher than that of control RPC without SSWs according to load-deflection relationships. The equivalent flexural strength of notched RPC beams is enhanced by $80.0 \%$ as SSW content increases from $1 \%$ to $1.5 \%$. The limitation ability of SSWs on crack mouth opening can be used to evaluate the flexural toughness of composites. An addition of $1.5 \%$ SSWs leads to $201.9 \%$ increase of flexural toughness of RPC plates in accordance with load-deflection relationships. The calculation model based on the composite material theory can accurately describe the toughening effect of SSWs on RPC beams and plates. The enhancement of flexural toughness of RPC caused by SSWs is beneficial for improving the safety of structures as well as broadening the engineering applications of composites.
\end{abstract}


Key words: Super-fine stainless wire; reactive powder concrete; flexural toughness; calculation model

\section{Introduction}

Flexural toughness is a measure of energy absorption capacity of concrete and is also used to characterize the crack resistance and ductility of concrete. This property of concrete is particularly important in applications such as structures subjected to static strains, earthquakes or explosive blasts, impact loads and other dynamic loads. Because of the brittle characteristic and low toughness, the engineering application of concrete is limited and the safety and applicability of structure elements is reduced.

The addition of randomly distributed fibers to concrete is an effective and economical method to reduce the brittleness and improve the deformation capacity and energy absorption of concrete. There have been considerable investigations on the flexural toughness properties of fiber reinforced concrete. Jang et al. [1] concluded that the equivalent flexural strength ratio of high strength concrete (HSC) increases with the increase of hooked-end steel fiber content, with an optimum content of $1.5 \%$ by volume. Kim et al. [2] employed four types of fibers to improve the flexural toughness of ultrahigh-performance concrete (UHPC). It was found that concretes reinforced with steel twisted fiber, high strength steel hooked-end fiber and high molecular weight polyethylene spectra fiber develop deflection-hardening characteristics at volume fraction of $0.4 \%$ and multiple cracks at volume fraction of $1.2 \%$. Steel twisted fiber reinforced concrete exhibits the highest energy absorption capacity at a deflection of 1/150 times of span (L/150), while spectra fiber reinforced concrete possesses the highest deflection capacity at the peak load. Banthia et al. [3] concluded that concrete reinforced with large and small diameter steel fibers 
demonstrates high toughness level than that reinforced with large diameter steel fibers alone, while the improvement result does not reach that of concrete reinforced with small diameter steel fibers alone. Li et al. [4] showed that green high-performance concrete (HPC) reinforced with 2 vol.\% polyvinyl alcohol (PVA) fibers retains well flexural toughness under severe earthquake situation due to the high interfacial bonding strength between fiber and matrix and the pulling out of fiber at failure state. The energy absorbing process of composites includes three stages, namely initiation of fine cracks, stable propagation of cracks and unstable propagation of cracks. In the study of Zhao et al. [5], the toughening effect of PVA fiber on concrete was achieved at volume fraction of $1.5 \%$. Zhang et al. [6] investigated the effect of fiber types and hybrid modes on flexural toughness of UHPC with coarse aggregates and concluded that 1.0 vol.\% hooked-end steel fibers blended with 1.0 vol.\% smooth steel fibers produces the best flexural toughness. Rashiddadash et al. [7] found that hybrid fiber reinforced concrete with 0.75 vol.\% steel fibers and 0.25 vol.\% polypropylene fibers has high flexural toughness. Kim et al. [8] compared the flexural toughness between bundle-type polyamide fiber reinforced concrete and hooked-end fiber reinforced concrete. The results showed that the equivalent flexural strength of concrete reinforced with $1.0 \%$ polyamide fibers is $5.84 \mathrm{MPa}$ while that of concrete reinforced with $1.0 \%$ hooked-end steel fibers is $10.31 \mathrm{MPa}$. Yap et al. [9] concluded that the hybrid addition of 0.9 vol.\% steel fibers and 0.1 vol.\% polypropylene (PP) hybrid fibers makes the toughness index of crushed and uncrushed oil palm shell concrete reach the highest values. In the investigation of Ding et al. [10], the self-compacting UHPC reinforced with $55 \mathrm{~kg} / \mathrm{m}^{3}$ macro steel fibers and $2 \mathrm{~kg} / \mathrm{m}^{3}$ micro PP fibers shows the highest ultimate load bending capacity after cracking and the highest flexural toughness values. Khan et al. [11] concluded that steel-PVA hybrid fiber reinforced 
UHPC shows higher flexural strength compared to steel-polyethylene (PE) hybrid fiber reinforced concrete, while the latter possesses higher flexural tensile strain hardening capacity than the former. Sivakumar and Santhanam [12] calculated the toughness and equivalent flexural strength for various fiber reinforced HSC. They found that the steel-PP fiber (with a low dosage of $0.12 \%$ ) reinforced concrete is tougher than mono-steel fiber reinforced concrete. Ahmed et al. [13] found that concrete with 1.0 vol.\% steel fibers and 1.5 vol.\% PVA fibers shows the highest flexural strength and that with $0.5 \%$ steel fibers and $2.0 \%$ PE fibers exhibits toughness index as high as 186. Wang et al. [14] studied the effect of modified multi-walled carbon nanotubes (MWCNTs) on the flexural toughness of cement specimens. They found that the addition of $0.08 \mathrm{wt} \%$ MWCNTs increases the flexural toughness index of composites by $57.5 \%$, while the toughness index of composites with 0.1 wt.\% MWCNTs is improved by $47.1 \%$. The modified multi-walled carbon nanotubes can bridge across cracks and voids to form a network and transfer load in tension.

In conclusion, flexural toughness is one of the key indexes to evaluate the practical engineering performance of $\mathrm{HSC} / \mathrm{HPC} / \mathrm{UHPC}$ including reactive powder concrete (RPC). The flexural toughness of concrete is enhanced by mixing steel fibers with different geometric sizes, hybrid steel fibers and organic fibers, and adding nano-materials in previous researches [1-14], making the preparation process of concrete complex and the production cost increase. Meanwhile, the addition of steel fibers with diameter larger than $0.22 \mathrm{~mm}$ generates weak interface zones in concrete [15-17], and the porosity of concrete is also increased due to the mixing incorporation of steel fibers and organic fibers [7]. Owing to the micron diameter, high aspect ratio and large specific surface area of super-fine stainless wire (SSW), the hydration 
reaction of concrete can be promoted and the matrix compactness can be improved. It is also noted that SSWs have thermal expansion coefficient similar to that of concrete matrix and high tensile strength. Moreover, SSWs have good dispersion in concrete and can form widely distributed strengthening and toughening network at low content [18-21]. The compactness improvement of concrete matrix caused by SSWs can effectively inhibit the generation of cracks. In addition, the SSW network in concrete can effectively transfer crack tip stresses and bridge macro cracks thus hindering the propagation of cracks. The inhibiting and bridging effect of SSW on the development of cracks is expected to greatly improve the flexural toughness of concrete. The enhancement of flexural toughness of SSW reinforced RPC will improve the deformation and survival ability of structural elements under the condition of maintaining a certain bearing capacity. Thus, the safety of structures will be enhanced, providing feasibility for structure security warns. Therefore, the flexural toughness of SSW reinforced RPC beams and plates was investigated in this paper, and the toughening calculation model was established on the basis of the composite material theory.

\section{Experimental schemes}

\subsection{Raw materials and mix proportion}

The cement used in this paper was ordinary Portland cement with strength grade of $42.5 \mathrm{R}$. The fly ash was class II fly ash. The average particle size of silica fume was $(0.1-0.3) \mu \mathrm{m}$. The particle diameter of quartz sand ranged from $0.12 \mathrm{~mm}$ to $0.83 \mathrm{~mm}$. The polycarboxylate superplasticizer was added in order to guarantee the fluidity of SSW reinforced RPC. The SSW with diameter of $20 \mu \mathrm{m}$ and length of $10 \mathrm{~mm}$ was processed by 316L stainless steel through strong drawing and shearing. 
According to the research of Richard [22], the ratio of cement: silica fume: quartz sand: water used in the current investigation was selected to be 1:0.25:1.1:0.3, of which $20 \%$ of cement was replaced by fly ash. The volume fraction of SSW was $0 \%, 1 \%$ and $1.5 \%$. The amount of superplasticizer was determined by the volume fraction of SSW to ensure that the electric jumping table fluidity of SSW reinforced RPC was $210 \pm 10 \mathrm{~mm}$.

The three RPC mixes studied were labelled as W0, W201010 and W201015, indicating RPC without SSW, with $1 \%$ and $1.5 \%$ of SSW, respectively.

\subsection{Specimens preparation}

The unnotched and notched beams with size of $40 \mathrm{~mm} \times 40 \mathrm{~mm} \times 160 \mathrm{~mm}$ were fabricated to test the flexural toughness of SSW reinforced RPC. Meanwhile, the plates with size of $400 \mathrm{~mm} \times 100 \mathrm{~mm} \times 15 \mathrm{~mm}$ were produced to evaluate the toughening effect of SSW on different types of RPC structural elements.

The mixing process of SSW reinforced RPC was the same as that referred to in references [18] and [19]. In order to acquire the middle notch during casting of beams, a $10 \mathrm{~mm}$ or $20 \mathrm{~mm}$ height flat steel plate having a $3 \mathrm{~mm}$ thickness was prepositioned at the middle of the molds. The crack length/depth ratio $\left(a_{0} / h, a_{0}=10 \mathrm{~mm}\right.$ or $20 \mathrm{~mm}$, $h=40 \mathrm{~mm}$ ) was 0.25 and 0.5 , respectively. The mixtures of composites were filled into oiled molds layer by layer and pressed. Then, the molds were vibrated for two minutes on the concrete vibration table and the mixture surface was smoothed by spatula. Next, the specimens were stored in a standard curing chamber and demoulded after 24 hours. After that, the hardened beams and plates were kept in accelerating curing box for 48 hours (the water temperature was $90{ }^{\circ} \mathrm{C}$ and temperature increase/decrease rate was $15^{\circ} \mathrm{C} / \mathrm{h}$ ). Later, the specimens were placed in room temperature environment for 28 days until the testing day. 


\subsection{Measurement of flexural toughness}

The evaluation methods of flexural toughness for fiber reinforced concrete based on load-deflection curve are mainly covered in ASTM-C1609 [23], JSCE-SF4 [24], RILEM TC162-TDF [25] and CECS13-2009 [26]. For the method of ASTM-C1609, the initial cracking point on load-deflection curve is difficult to be accurately identified. For JSCE-SF4, the calculated flexural toughness factor is significantly affected by the specimen geometry and the end-point deflection of L/150 used for computation is much greater than the deflection at serviceability [27]. The notched beams are tested in the method of RILEM TC162-TDF, but the relationship between mid-span deflection $(\delta)$ and crack mouth opening displacement $(C M O D)$ in this method is only applied to normal steel fiber reinforced concrete. The flexural toughness of unnotched beam in CECS13-2009 is evaluated according to ASTM-C1609 and the notched beam experiment is specified on the basis of RILEM TC162-TDF.

However, there is no a standard evaluation method for the flexural toughness of RPC to-date. In order to avoid the inaccuracy of initial cracking point and obtain the comprehensive toughening effect of SSW on RPC, the flexural toughness in this paper was calculated by the integration of load-deflection/displacement curve without considering the influence of curve tail. It should be note that the deflection in this investigation was referred to the mid-span deformation of beams and plates obtained by linearly varying displacement transducer (LVDT), while the displacement was the deformation value achieved by built-in displacement sensor of electronic universal testing machine. For unnotched beams and plates under four-point bending load, the flexural toughness (in $\mathrm{J} / \mathrm{m}^{2}$ ) obtained by the integral area of load-deflection/displacement curves under peak load was defined as peak flexural 
toughness, and that obtained by the total integral area of load-deflection/displacement curves was referred to limit flexural toughness. Meanwhile, the notched beams were tested on the basis of CECS13-2009 in this paper, as the existence of notch could accurately determine the crack location and analyze the crack resistance of SSW. The relationship between $\delta$ and $C M O D$ for SSW reinforced RPC was obtained through linear fitting. Fig. 1 shows the beam and plate loading diagram for flexural toughness test. As demonstrated in Fig. 1(a), the mid-span deflection of unnotched beams for SSW reinforced RPC was measured using linearly varying displacement transducer (LVDT) under a four-point bending load system. It can be seen from Fig. 1(b) that clip gauge and LVDT were used to measure the $C M O D$ and mid-span deflection of notched beams under a three-point bending load system. Two knife edges were glued to both sides of the notch in order to fix clip gauge. The mid-span deflection of plates under a four-point bending load system was also obtained using LVDT, as displayed in Fig. 1(c). Data acquisition system (DH 3820) was employed to collect the values of $C M O D$ and mid-span deflection. In addition, the mid-span displacement of unnotched beams and plates was obtained by the built-in displacement sensor of electronic universal testing machine. The loading procedure was controlled by displacement at a rate of $0.05 \mathrm{~mm} / \mathrm{min}$. The sampling rate of load, deflection, displacement and CMOD was $2 \mathrm{~Hz}$.

There were three identical specimens for each concrete mix and element type. The load-deflection/displacement/CMOD curve closest to the average one was analyzed to obtain the crack resistance effect of SSW on RPC. The equivalent flexural strength of notched beams was acquired on the basis of the above selected load-deflection/CMOD curve to ensure the consistency of results. The flexural toughness average value of three specimens for each concrete mix and element type 
was regarded as the final result if the difference between average and the maximum and the minimum values was less than $15 \%$. If one difference is more than $15 \%$, the median was determined as the final value, and if two differences are all more than $15 \%$, this group of data is invalid.

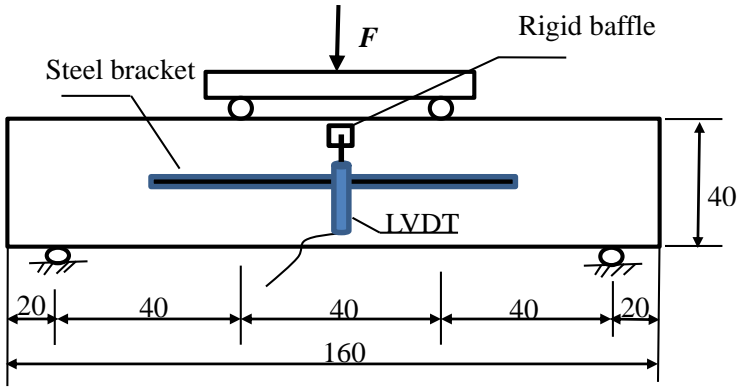

(a) Unnotched beam under four-point bending load

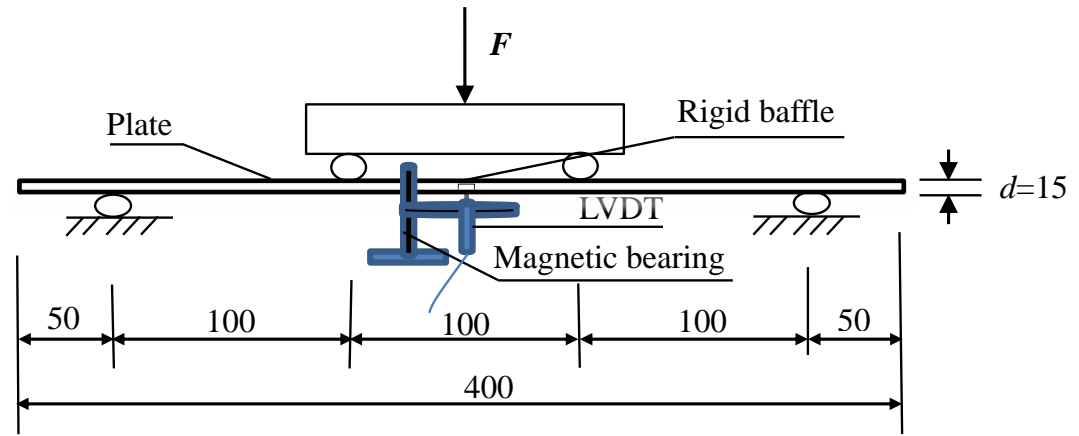

(c) Plate under four-point bending load

Fig. 1 Loading diagram of flexural toughness test (Unit:mm)

\section{Test results of flexural toughness}

\subsection{Four-point bending unnotched beam test results}

The bending strength, load-deflection curves and flexural toughness of unnotched beams of SSW reinforced RPC under four-point bending load are plotted in Fig. 2. Fig. 2(a) displays that the bending strength of RPC are improved by $13.5 \%$ and $36.6 \%$ due to the incorporation of $1 \%$ and $1.5 \%$ SSWs. As shown in Fig. 2(b), the deflection of composites at peak load is $10.9 \%$ and $39.3 \%$ higher than that of control RPC, and the limit deflection (as marked in Fig. 2(b)) of RPC is enhanced by $18.2 \%$ and 58.9\%, respectively. There are obvious non-linear ascending stage and stationary 
stage before peak load on load-deflection curve of RPC reinforced with $1.5 \%$ SSWs. During the stationary stage of load-deflection curve, the tensile stress has been completely transferred to SSWs and the composite shows a strain hardening characteristic. The corresponding failure beams manifest multi-cracking tendency. At the peak load, the RPC beams without SSW sharply fail, losing any resistance as indicated in Fig. 2(b). However, the slow descending stage on load-deflection curve prolongs with the increasing of SSW content, reflecting the gradual rupture of bridging SSWs.

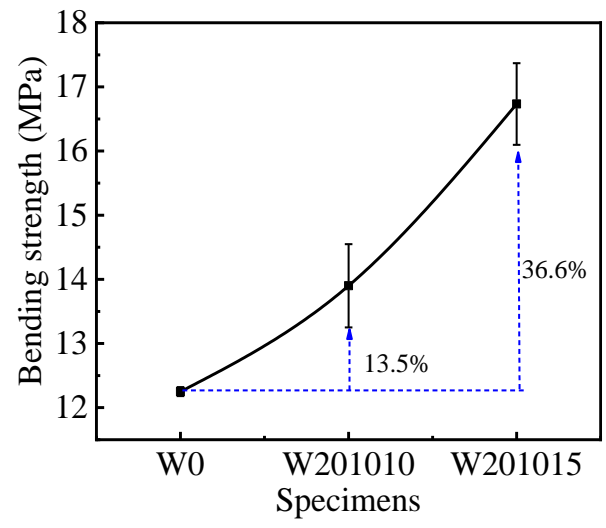

(a) Bending strength

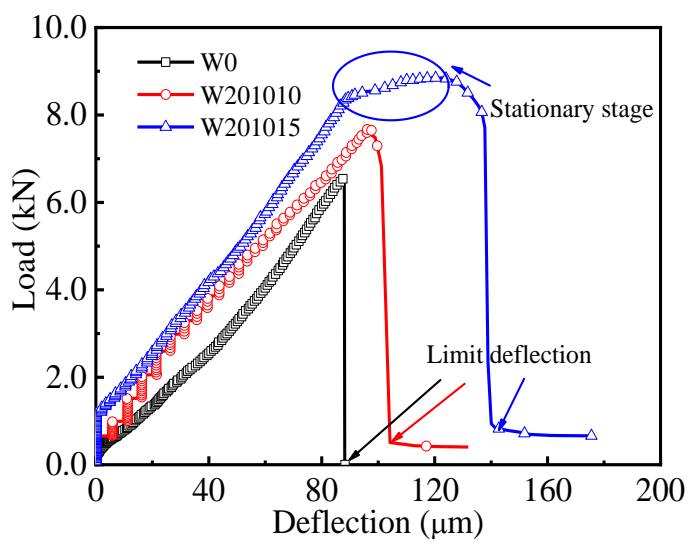

(b) Load-deflection curve

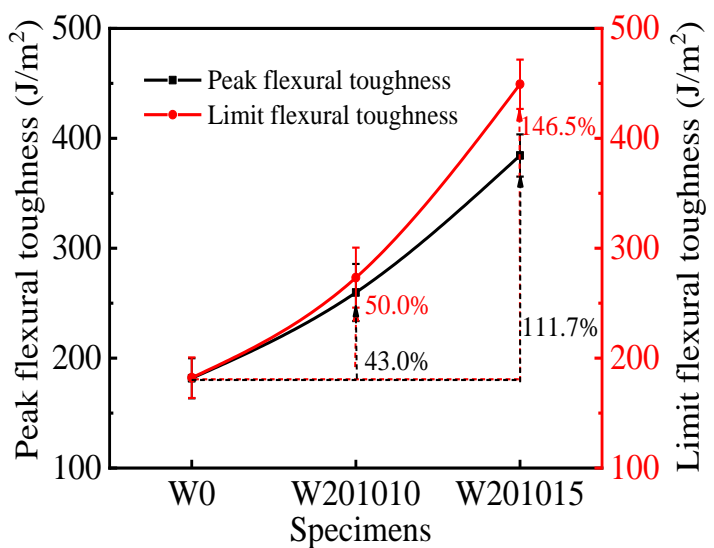

(c) Flexural toughness

Fig. 2 Bending strength, load-deflection curves and flexural toughness of SSW reinforced RPC under four-point bending load

It can be seen form Fig. 2(c) that the peak flexural toughness of RPC reinforced with $1 \%$ and $1.5 \%$ SSWs is $43.0 \%$ and $111.7 \%$ higher than that of RPC without SSW. 
Meanwhile, the limit flexural toughness increases are $50.0 \%$ and $146.5 \%$ for $1 \%$ and $1.5 \%$ SSWs addition, respectively. The ratios of peak flexural toughness to limit flexural toughness are $99.7 \%, 95.0 \%$ and $85.6 \%$ for RPC reinforced with $0 \%, 1 \%$ and $1.5 \%$ SSWs, respectively, reflecting the bearing capacity enhancement of composites after cracking. This can be ascribed to the inhibiting and bridging effect of SSWs on crack development. The improvement of limit flexural toughness for RPC reinforced with $1 \%$ SSWs is mainly attributed to the increase of peak load, while that for RPC reinforced with $1.5 \% \mathrm{SSWs}$ is related to both the increase of peak load and the enhancement of bearing capacity after cracking.

The load-displacement curves and the corresponding flexural toughness of unnotched beams for SSW reinforced RPC under four-point bending load are given in Fig. 3. Fig. 3(a) indicates that the slope of linear-ascending stage of load-displacement curves is improved slightly due to the addition of $1 \%$ SSWs. Meanwhile, the load-displacement curve of RPC reinforced with $1.5 \%$ SSWs possesses obvious non-linear ascending stage. This is because that the SSWs with 1 vol.\% have achieved remarkable enhancement effect on RPC matrix, while the inhibiting effect of SSWs on the initiation and propagation of cracks can be fully developed at the volume fraction of $1.5 \%$. The load-displacement curve of control RPC instantaneously drops after peak load, while that of RPC reinforced with $1.5 \%$ SSWs first exhibits slow descending trend and then drops linearly, confirming that the bridging effect of SSWs on cracks can effectively control the propagation of macro cracks. The peak displacements of RPC reinforced with $1 \%$ and $1.5 \%$ SSWs are increased by $4.7 \%$ and $15.8 \%$, respectively compared to that of RPC without SSW. 


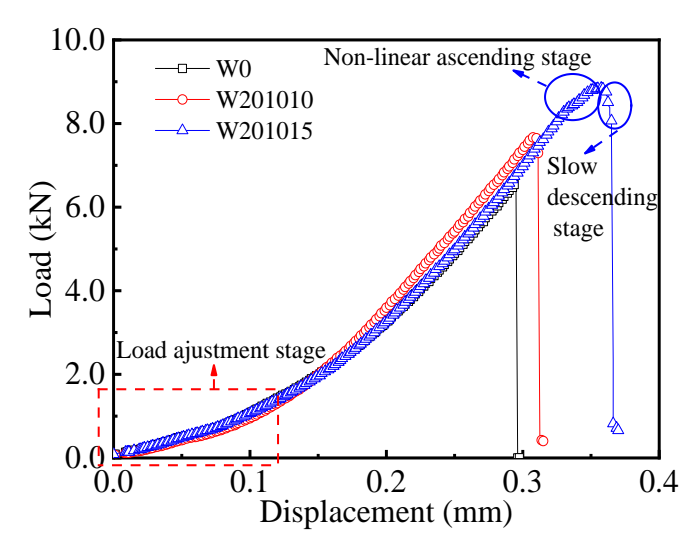

(a) Load-displacement curves

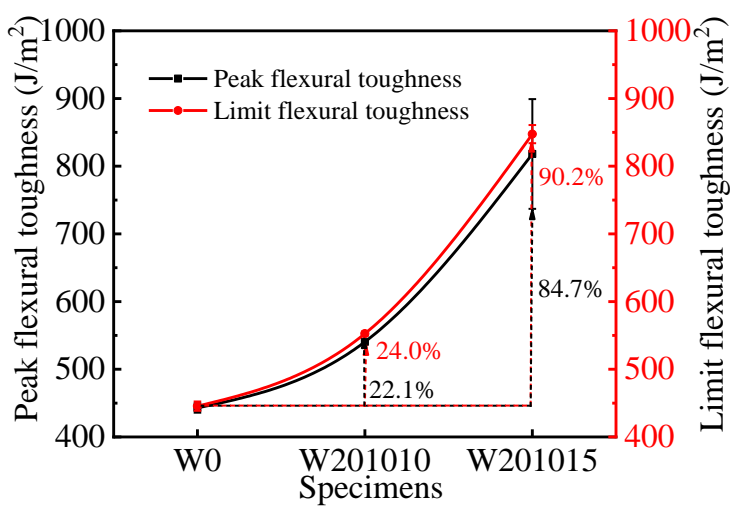

(b) Flexural toughness

Fig. 3 Load-displacement curves and flexural toughness of SSW reinforced RPC under four-point bending load

As shown in Fig. 3(b), the flexural toughness of SSW reinforced RPC calculated on the basis of load-displacement curves exhibits the same variation with that calculated according to load-deflection curves, while the values of limit flexural toughness are improved by $144.5 \%, 102.3 \%$ and $88.6 \%$ for RPC reinforced with $0 \%$, $1 \%$ and $1.5 \%$ SSWs, respectively. The improvement of deformation ability for RPC caused by SSWs reduces the effect of equipment deformation on the values of flexural toughness. The addition of $1 \%$ and $1.5 \%$ SSWs leads to $22.1 \%$ and $84.7 \%$ increase for peak flexural toughness as well as $24.1 \%$ and $90.2 \%$ increase for limit flexural toughness, respectively. The ratios of peak flexural toughness to limit flexural toughness are $99.4 \%, 97.8 \%$ and $96.5 \%$ for RPC reinforced with $0 \%, 1 \%$ and $1.5 \%$ SSWs, respectively.

The cracking pattern of unnotched beams of SSW reinforced RPC after failure is displayed in Fig. 4. It can be observed from Fig. 4 that the failure crack width is decreased and the propagation path of cracks is prolonged due to the incorporation of SSWs. The failure cracks become more tortuous and the fracture surfaces become unsmooth with the SSW content increases. Meanwhile, the cracks do not penetrate the 
entire section of beams for RPC reinforced with SSWs and the rupture SSWs can be observed on the crack surface.

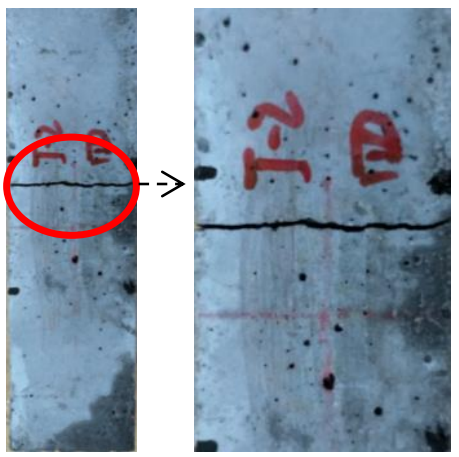

a) W0

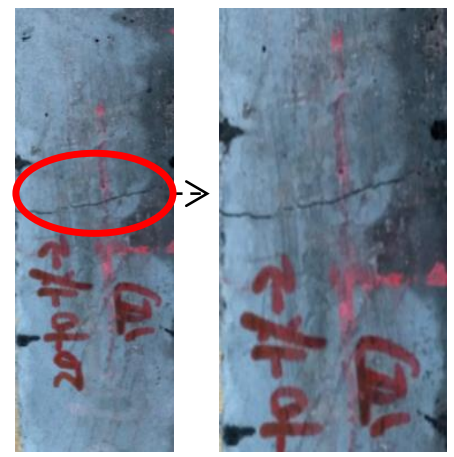

(b) W201010
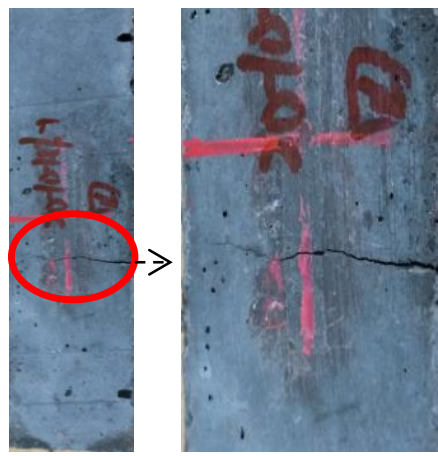

(c) W201015

Fig. 4 Cracking patterns of SSW reinforced RPC under four-point bending load

\subsection{Three-point bending notched beam test results}

\subsubsection{Specimens with crack length/depth ratio of 0.25}

At the crack length/depth ratio of 0.25 , the load-deflection curves, flexural strength and peak deflection of notched beams of SSW reinforced RPC under three-point bending load are plotted in Fig. 5. Owing to the inhibiting effect of SSWs on crack development, the load-deflection curves of RPC reinforced with SSWs exhibit long linear ascending stage, obvious non-linear ascending stage and slow descending stage, as shown in Fig. 5(a). The peak deflection RPC is improved due to the presence of SSWs. The stationary stage before peak load on load-deflection curves is more obvious with the SSW content increasing, indicating the occurrence of yield state for SSW reinforced RPC. Following Fig. 5(b), it is clear that the increases of $73.9 \%$ and $119.9 \%$ are obtained for the flexural strength of SSW reinforced RPC compared to that of RPC without SSW. The enhancement ratios of peak deflection caused by $1 \%$ and $1.5 \%$ SSWs are $17.3 \%$ and $95.2 \%$, respectively. 


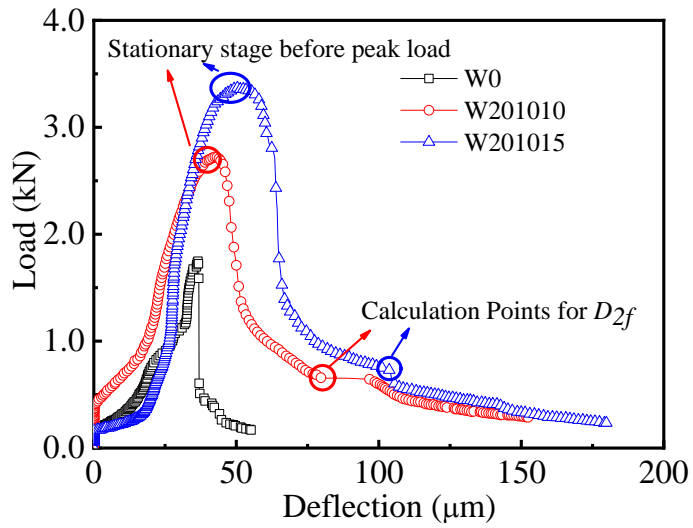

(a) Load-deflection curve

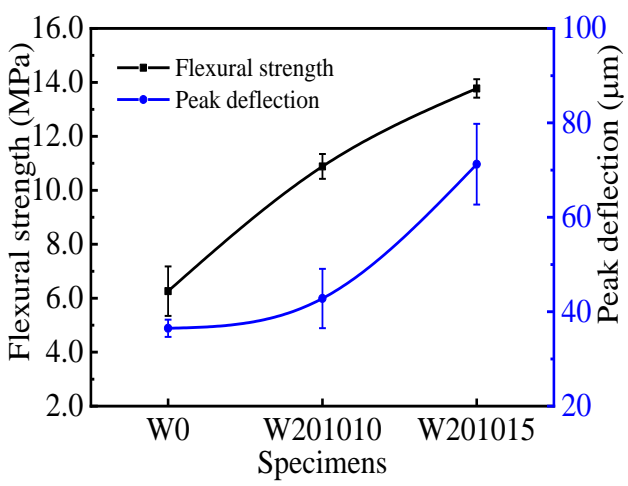

(b) Flexural strength and peak deflection

Fig. $5 a_{0} / h=0.25$, load-deflection curves, flexural strength and peak deflection of notched beams for SSW reinforced RPC

Based on CECS13-2009, the energy absorption and equivalent flexural strength of notched beams of SSW reinforced RPC are calculated considering the following assumptions. (1) Due to the non-standard size of notched beam used in this paper, the integral area of load-deflection curve for RPC without SSW is defined as the energy absorption of matrix cracking $D_{c r}$. (2) The energy absorption calculated by load-deflection curves of SSW reinforced RPC under peak load is marked as $D_{l f \text {. (3) }}$ It can be observed from Fig. 5(a) that the load-deflection curves are difficult to be zero because of the insufficient rigidity of testing machine. After dropping to a certain point, there is a sudden change in the value of deflection, indicating that the beams step into in failure state. In order to fully reflect the toughening effect of SSW with different content, the different failure points on load-deflection curves of RPC reinforced with $1 \%$ and $1.5 \%$ SSWs are adopted to calculate energy absorption $D_{2 f}$. Meanwhile, the deflections corresponding to $D_{c r}$ on load-deflection curves of SSW reinforced RPC are denoted as $\delta_{u}$. The peak deflections are denoted as $\delta_{u 1}$ and the equivalent flexural strength calculated by $D_{l f}$ is $f_{e q 1}$. The deflection and equivalent flexural strength corresponding to $D_{2 f}$ are $\delta_{u 2}$ and $f_{e q 2}$, respectively. The average value of total integral area for three beams with the same concrete mix under 
load-deflection curve is denoted as $\bar{D}$. Of which, the equivalent flexural strength is calculated by the following Equations (1) and (2).

$$
\begin{gathered}
f_{e q 1}=\frac{D_{l f}-D_{c r}}{\delta_{u 1}-\delta_{u}} \times \frac{1.5 L}{B h^{2}} \\
f_{e q 2}=\frac{D_{2 f}-D_{c r}}{\delta_{u 2}-\delta_{u}} \times \frac{1.5 L}{B h^{2}}
\end{gathered}
$$

where $L$ is the span of notched beam; $B$ is the width of notched beam; $h$ is the effective height of notched beam, which equals to beam height minus notch height.

Table $1 a_{0} / h=0.25$, equivalent flexural strength of SSW reinforced RPC

\begin{tabular}{cccccccccc}
\hline Specimens & $\begin{array}{c}D_{c r} \\
/ \mathrm{N} \cdot \mathrm{mm}\end{array}$ & $\begin{array}{c}\delta_{u} \\
/ \mu \mathrm{m}\end{array}$ & $\begin{array}{c}D_{l f} \\
/ \mathrm{N} \cdot \mathrm{mm}\end{array}$ & $\begin{array}{c}\delta_{u 1} \\
/ \mu \mathrm{m}\end{array}$ & $\begin{array}{c}f_{e q 1} \\
/ \mathrm{MPa}\end{array}$ & $\begin{array}{c}D_{2 f} \\
/ \mathrm{N} \cdot \mathrm{mm}\end{array}$ & $\begin{array}{c}\delta_{u 2} \\
/ \mu \mathrm{m}\end{array}$ & $\begin{array}{c}f_{\text {eq2 }} \\
/ \mathrm{MPa}\end{array}$ & $\begin{array}{c}\bar{D}(\text { Standard } \\
\text { deviation }) \\
/ \mathrm{N} \cdot \mathrm{mm}\end{array}$ \\
\hline $\mathrm{W} 0$ & 29.9 & - & - & - & - & - & - & - & $32.0(2.80)$ \\
$\mathrm{W} 201010$ & 29.9 & 29.7 & 64.4 & 43.4 & 8.6 & 114.7 & 89.3 & 5.9 & $106.9(11.26)$ \\
$\mathrm{W} 201015$ & 29.9 & 36.2 & 74.8 & 50.4 & 13.2 & 157.6 & 104.0 & 7.8 & $173.1(10.34)$ \\
\hline
\end{tabular}

The energy absorption and equivalent flexural strength of RPC composites at the crack length/depth ratio of 0.25 are listed in Table 1 . As shown in Table 1, the energy absorption difference between $D_{l f}$ and $D_{c r}$ for RPC reinforced with $1.5 \% \mathrm{SSWs}$ is increased by $16.1 \%$ compared to that for RPC reinforced with $1.0 \%$ SSWs, reflecting the enhancement effect of SSW on RPC matrix and the inhibiting effect of SSW on the initiation and stable propagation of cracks. Meanwhile, the increase of SSW content leads to $37.4 \%$ increase for energy absorption difference between $D_{2 f}$ and $D_{c r}$, and this difference can be mainly ascribed to bridging effect of SSWs. The equivalent flexural strength represents the ability of composites to resist deformation in plastic stage. The equivalent flexural strength corresponding to energy absorption $D_{1 f}$ and $D_{2 f}$ of RPC reinforced with $1.5 \%$ SSWs is $53.5 \%$ and $32.2 \%$ higher than that of RPC reinforced with $1.0 \%$ SSWs. The improvement of energy absorption and equivalent flexural strength caused by SSWs can be attributed to the following phenomenon. (1) 
The original flaw in RPC matrix is reduced and the anti-cracking ability of matrix is enhanced due to the micron diameter and large specific surface area of SSW. (2) The SSWs can effectively transfer the crack tip stresses and inhibit the initiation and propagation of cracks. The propagation path of cracks is prolonged and this endows RPC with large plastic displacement capacity. (3) With the formation of macro cracks, tensile stress is mainly undertaken by SSWs and the load-deflection curve displays stationary stage before peak load and slow descending stage after peak load. The load drops sharply with the rupture of SSW, while the beams still remain intact when failure occurs.

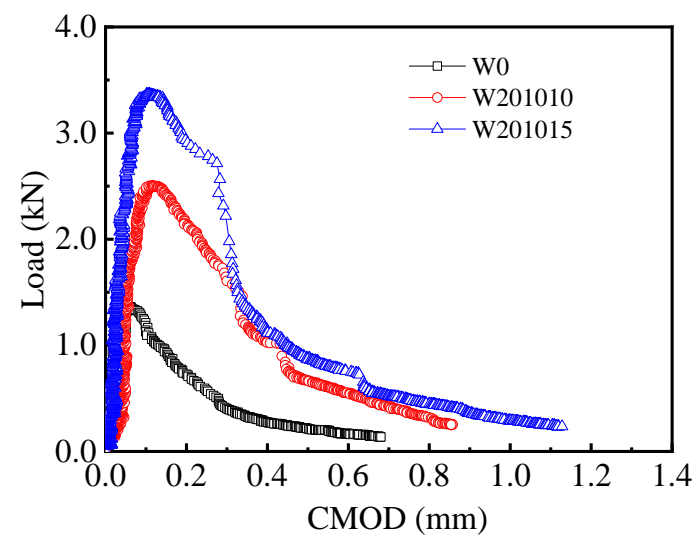

Fig. $6 a_{0} / h=0.25$, load-CMOD curves of SSW reinforced RPC under three-point bending load

The load-CMOD curves of SSW reinforced RPC at the crack length/depth ratio of 0.25 are demonstrated in Fig. 6. It is evident from Fig. 6 that the variation of load-CMOD curves caused by the addition of SSW is similar to that of load-deflection curves. The load-CMOD curve of RPC reinforced with $1.5 \%$ SSWs contains three stages including linear ascending stage, non-linear ascending stage and slow descending stage. If the load-CMOD curve can also be used to characterize the flexural toughness of notched beam, the evaluation indexes are more comprehensive and reliable. However, the recommended relationship between $\delta$ and $C M O D$ in the method of RILEM TC162-TDF and CECS 13-2009 is not applicable to SSW 
reinforced RPC. According to fracture mechanics, the theoretical calculation model between flexural deflection $\delta$ and $C M O D$ of concrete beams is plotted in Fig. 7 [28].

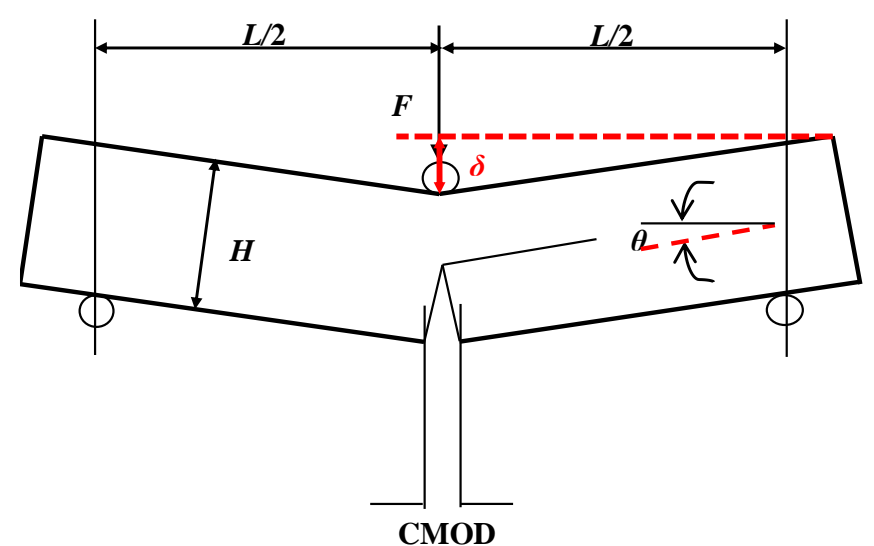

Fig. 7 Theoretical calculation model between deflection and CMOD [28]

$$
\begin{gathered}
\tan \theta=\frac{\delta}{l / 2}=\frac{C M O D / 2}{H} \\
C M O D=\frac{4 \delta H}{L}
\end{gathered}
$$

It can be seen from Fig. 7 and Equation (4) that there exists linear correlation between $\delta$ and $C M O D$, that can be used to obtain the characteristic points on load-CMOD curve for calculating energy absorption and equivalent flexural strength. The fitting relationship between $\delta$ and $C M O D$ of SSW reinforced RPC is given in Fig. 8. As demonstrated in Fig. 8, CMOD shows approximately three-stage linear behavior with $\delta$, corresponding to the three stages of crack development, including elastic stage, stable crack propagation stage and unstable crack propagation stage. 

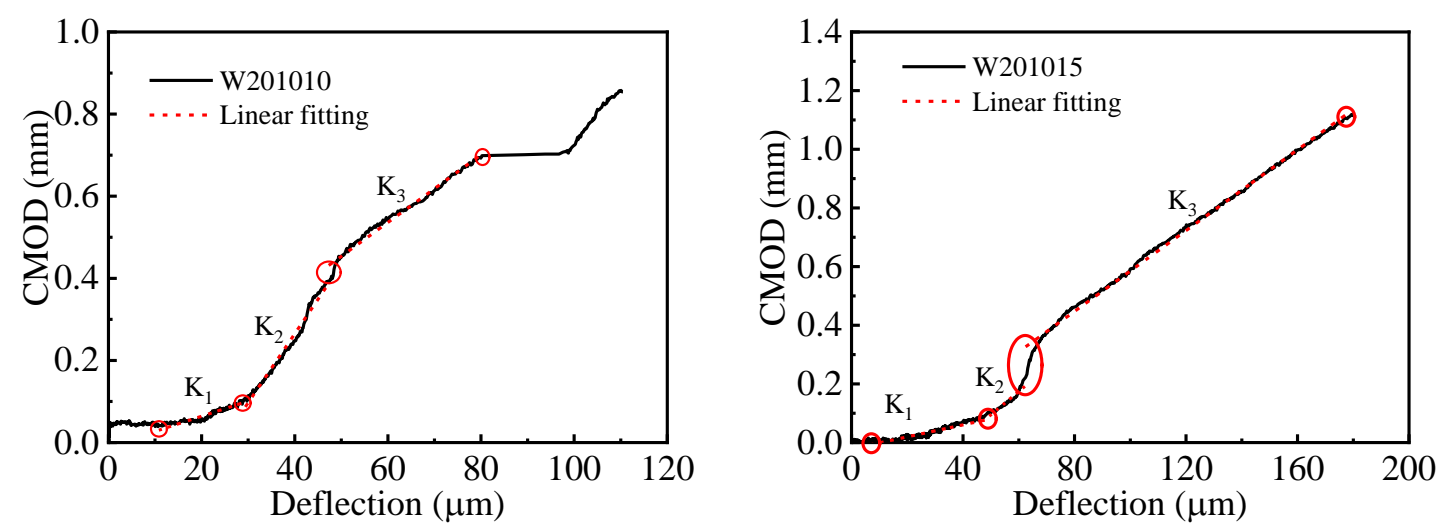

Fig. $8 a_{0} / h=0.25$, the fitting relationship between $\delta$ and $C M O D$ of SSW reinforced RPC

The linear slopes corresponding to the above three stages are marked as $\mathrm{K}_{1}, \mathrm{~K}_{2}$ and $K_{3}$, respectively as shown in Fig. 8. The values of $K_{1}, K_{2}$ and $K_{3}$ are listed in Table 2. Table 2 shows that the values of $\mathrm{K}$ first increase and then decrease with $\delta$ increases. The increasing of SSW content leads to $80.0 \%, 111.0 \%$ and $15.7 \%$ reduction of $\mathrm{K}$ values, indicating that high volume fraction of SSW can limit the opening of crack mouth more effectively especially in the stage of unstable crack propagation.

Table $2 a_{0} / h=0.25$, fitting equations between $\delta$ and $C M O D$ of SSW reinforced RPC

\begin{tabular}{ccccc}
\hline Specimens & Fitting equation & $\mathrm{K}$ & Deflection range & $\mathrm{R}^{2}$ \\
\hline \multirow{3}{*}{ W201010 } & $C M O D=0.00369 \delta-0.00969$ & $\mathrm{~K}_{1}=0.00369$ & $(10.80,30.51]$ & 0.89845 \\
& $C M O D=0.01680 \delta-0.40692$ & $\mathrm{~K}_{2}=0.01680$ & $(30.51,47.31]$ & 0.98225 \\
& $C M O D=0.00772 \delta+0.07754$ & $\mathrm{~K}_{3}=0.00772$ & $(47.31,108.90]$ & 0.99408 \\
\hline \multirow{3}{*}{ W201015 } & $C M O D=0.00205 \delta-0.02136$ & $\mathrm{~K}_{1}=0.00205$ & $(0,49.23]$ & 0.85202 \\
& $C M O D=0.00796 \delta-0.30321$ & $\mathrm{~K}_{2}=0.00796$ & $(49.23,62.45]$ & 0.91213 \\
& $C M O D=0.00667 \delta-0.07259$ & $\mathrm{~K}_{3}=0.00667$ & $(62.45,178.15]$ & 0.99926 \\
\hline
\end{tabular}

The characteristic values of $C M O D$ are calculated according to the fitting results between $\delta$ and $C M O D$, which are listed in Table 3. Then, the energy absorption and equivalent flexural strength of SSW reinforced RPC are analyzed in accordance with load-CMOD curves, and the calculation equations are the same as Equations (1) and (2). The calculation results are shown in Table 4. 
Table $3 a_{0} / h=0.25$, characteristic values of $C M O D$ corresponding to $\delta$

\begin{tabular}{ccccccc}
\hline Specimens & $\begin{array}{c}\delta_{u} \\
/ \mu \mathrm{m}\end{array}$ & $\begin{array}{c}C M O D_{u} \\
/ \mathrm{mm}\end{array}$ & $\begin{array}{c}\delta_{u 1} \\
/ \mu \mathrm{m}\end{array}$ & $\begin{array}{c}C M O D_{1} \\
/ \mathrm{mm}\end{array}$ & $\begin{array}{c}\delta_{u 2} \\
/ \mu \mathrm{m}\end{array}$ & $\begin{array}{c}\mathrm{CMOD}_{2} \\
/ \mathrm{mm}\end{array}$ \\
\hline $\mathrm{W} 201010$ & 29.7 & 0.0999 & 43.4 & 0.3216 & 89.3 & 0.7671 \\
$\mathrm{~W} 201015$ & 36.2 & 0.0528 & 50.4 & 0.0978 & 104.0 & 0.6213 \\
\hline
\end{tabular}

Table $4 a_{0} / h=0.25$, energy absorption and equivalent flexural strength of SSW reinforced RPC based on load-CMOD curves

\begin{tabular}{cccccc}
\hline \multirow{2}{*}{ Specimens } & $\begin{array}{c}D_{c r} \\
/ \mathrm{kN} \cdot \mathrm{mm}\end{array}$ & $\begin{array}{c}D_{l f} \\
/ \mathrm{kN} \cdot \mathrm{mm}\end{array}$ & $\begin{array}{c}D_{2 f} \\
/ \mathrm{kN} \cdot \mathrm{mm}\end{array}$ & $\begin{array}{c}f_{\text {eql }} \\
/ \mathrm{MPa}\end{array}$ & $\begin{array}{c}f_{\text {eq2 }} \\
/ \mathrm{MPa}\end{array}$ \\
\hline $\mathrm{W} 201010$ & 0.1081 & 0.5779 & 0.8928 & 8.8 & 4.9 \\
$\mathrm{~W} 201015$ & 0.0658 & 0.2017 & 1.1451 & 12.6 & 7.9 \\
\hline
\end{tabular}

As can be observed from Table 4 , the energy absorption $D_{2 f}$ of RPC reinforced with $1.5 \%$ SSWs is $28.3 \%$ higher than that of RPC reinforced with $1.0 \%$ SSWs. The equivalent flexural strength $f_{\text {eq1 }}$ ' and $f_{\text {eq2 }}$ ' show an increase of $43.2 \%$ and $61.2 \%$ with the increasing SSW volume fraction. With the increase of $C M O D$, the equivalent flexural strength of SSW reinforced RPC decreases because of the rupture of SSWs.

The relative errors for equivalent flexural strength can be calculated using Equations (5) and (6), and the values of relative error are given in Table 5. Table 5 exhibits that the relative error for RPC reinforced with $1.0 \%$ SSWs is less than $16.2 \%$, while that for RPC reinforced with $1.5 \%$ SSWs is less than $4.5 \%$. Therefore, the flexural toughness of notched beams for SSW reinforced RPC can be evaluated either by load-deflection curve or by load-CMOD curve. Using $\delta$ and $C M O D$ simultaneously to evaluate the flexural toughness of SSW reinforced RPC improves the accuracy and reliability of test results. In addition, the testing machine is simplified and the test cost is reduced by directly using $C M O D$ to evaluate the flexural toughness of notched beams.

$$
\Delta f_{e q 1}=\frac{\left|f_{e q 1}-f_{e q 1}^{\prime}\right|}{f_{e q 1}}
$$




$$
\Delta f_{e q 2}=\frac{\left|f_{e q 2}-f_{e q 2}^{\prime}\right|}{f_{e q 2}}
$$

Table $5 a_{0} / h=0.25$, relative errors of equivalent flexural strength

\begin{tabular}{ccccccc}
\hline \multirow{2}{*}{ Specimens } & \multicolumn{2}{c}{ Based on $\delta$} & \multicolumn{2}{c}{ Based on CMOD } & \multicolumn{2}{c}{ Relative error } \\
& $f_{\text {eq } 1} / \mathrm{MPa}$ & $f_{\text {eq } 2} / \mathrm{MPa}$ & $f_{\text {eq1 }} / \mathrm{MPa}$ & $f_{\text {eq } 2} / \mathrm{MPa}$ & $\Delta f_{\text {eq } 1}$ & $\Delta f_{\text {eq } 2}$ \\
\hline $\mathrm{W} 201010$ & 8.6 & 5.9 & 8.8 & 4.9 & $2.3 \%$ & $16.2 \%$ \\
$\mathrm{~W} 201015$ & 13.2 & 7.8 & 12.6 & 7.9 & $4.5 \%$ & $1.3 \%$ \\
\hline
\end{tabular}

\subsubsection{Specimens with crack length/depth ratio of 0.5}

At the crack length/depth ratio of 0.5 , the load-deflection curves, flexural strength, peak deflection and load-CMOD curves of notched beams for SSW reinforced RPC are demonstrated in Fig. 9. Fig. 9(a) and (c) indicate that the notched beam of RPC without SSW has a low bearing capacity. The load-deflection and load-CMOD curves of SSW reinforced RPC beams possess long linear ascending stage, obvious non-linear ascending stage and slow descending stage. This toughening phenomenon caused by SSWs is not affected by the crack length/depth ratio and can be attributed to the inhibiting effect of SSW on the initiation and propagation of cracks. It can be seen from Fig. 9(b) that the flexural strength of RPC is improved by $65.2 \%$ and $74.4 \%$ due to the addition of $1 \%$ and $1.5 \%$ SSWs, respectively. The peak deflection of RPC without SSW is only $2.1 \mu \mathrm{m}$, increasing to $39.0 \mu \mathrm{m}$ and $58.7 \mu \mathrm{m}$ for RPC reinforced with $1 \%$ and $1.5 \%$ SSWs, respectively.

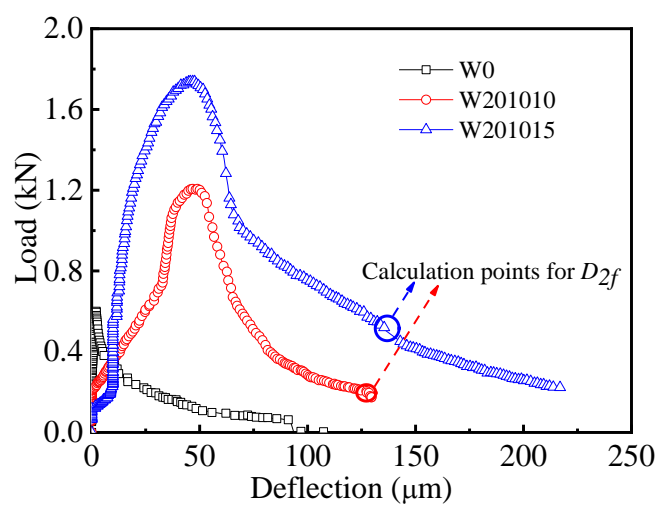

(a) Load-deflection curve

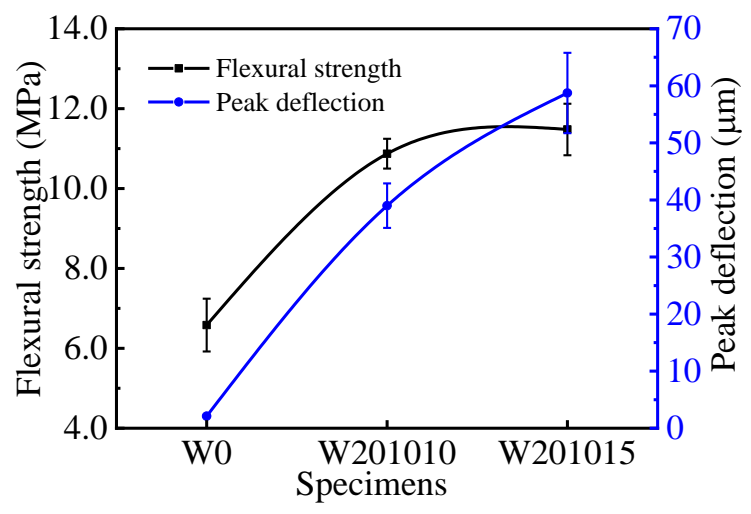

(b) Flexural strength and peak deflection 


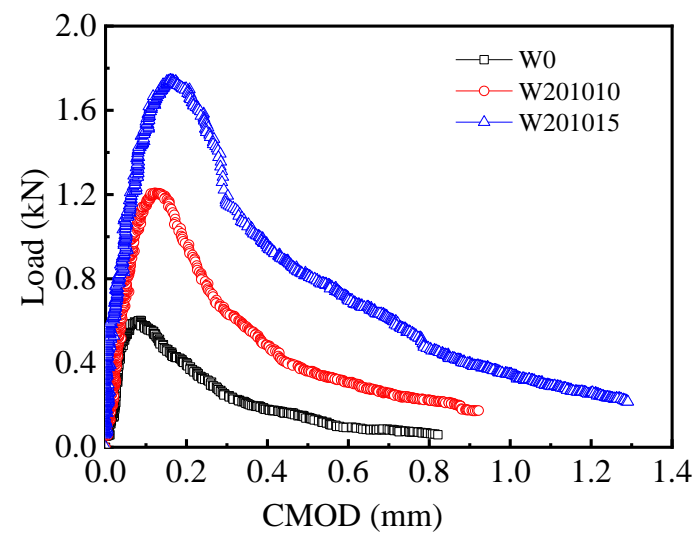

(c) Load-CMOD curve

Fig. $9 a_{0} / h=0.5$, load-deflection curves, flexural strength, peak deflection and load-CMOD curves of SSW reinforced RPC

The energy absorption and equivalent flexural strength of SSW reinforced RPC at the crack length/depth ratio of 0.5 are calculated following Equations (1) and (2), and the results are listed in Table 6. Table 6 illustrates that the deflection corresponding to matrix energy absorption $D_{c r}$ decreases with the SSW content increases. In the crack stable propagation stage, the energy absorption $D_{l f}$ of RPC reinforced with $1.5 \%$ SSWs is $63.5 \%$ higher than that of RPC reinforced with $1 \%$ SSWs. In the crack unstable propagation stage, the increase of SSW content leads to 93.7\% increase of energy absorption $D_{2 f}$. The equivalent flexural strength $f_{e q 1}$ and $f_{e q 2}$ are increased by $41.1 \%$ and $80.0 \%$, respectively, because of the increasing SSW content. SSWs can not only inhibit the initiation and propagation of cracks, but also bridge cracks until ruptured, eventually resulting in the enhancement of flexural toughness of RPC.

Table $6 a_{0} / h=0.5$, equivalent flexural strength of SSW reinforced RPC

\begin{tabular}{cccccccccc}
\hline \multirow{2}{*}{ Specimens } & $\begin{array}{c}D_{c r} \\
/ \mathrm{N} \cdot \mathrm{mm}\end{array}$ & $\delta_{u}$ & $\begin{array}{c}D_{l f} \\
/ \mu \mathrm{m}\end{array}$ & $\begin{array}{c}\delta_{u 1} \\
/ \mathrm{N} \cdot \mathrm{mm}\end{array}$ & $\begin{array}{c}f_{\text {eq1 }} \\
/ \mu \mathrm{m}\end{array}$ & $\begin{array}{c}D_{2 f} \\
/ \mathrm{MPa}\end{array}$ & $\begin{array}{c}\delta_{u 2} \\
/ \mathrm{N} \cdot \mathrm{mm} \\
/ \mu \mathrm{m}\end{array}$ & $\begin{array}{c}f_{\text {eq2 }} \\
/ \mathrm{MPa}\end{array}$ & $\begin{array}{c}\bar{D}(\text { Standard } \\
\text { deviation) } \\
/ \mathrm{N} \cdot \mathrm{mm}\end{array}$ \\
\hline $\mathrm{W}$ & 15.8 & - & - & - & - & - & - & - & $19.7(0.70)$ \\
$\mathrm{W} 201010$ & 15.8 & 33.6 & 32.9 & 49.0 & 10.7 & 69.8 & 125.1 & 5.5 & $85.6(9.26)$ \\
$\mathrm{W} 201015$ & 15.8 & 23.7 & 53.8 & 47.3 & 15.1 & 135.2 & 136.3 & 9.9 & $220.1(10.60)$ \\
\hline
\end{tabular}


In accordance with Equation (4), the linear fitting between $\delta$ and $C M O D$ is carried out for notched beams with crack length/depth ratio of 0.5 . The fitting curves are plotted in Fig. 10 and the fitting results are displayed in Table 7. As observed in Fig. 10, there is a three-stage linear relationship between $\delta$ and $C M O D$ of RPC reinforced with $1 \%$ and $1.5 \%$ SSWs. Table 7 shows that the slopes $\left(K_{1}, K_{2}\right.$ and $\left.K_{3}\right)$ of linear fitting are decreased by $3.0 \%, 29.9 \%$ and $34.1 \%$ respectively at different stages with the increasing SSW content. The RPC composite reinforced with high content SSWs yields large deformation ability and high inhibition capacity on the opening of crack mouth. The values of $\mathrm{K}_{1}, \mathrm{~K}_{2}$ and $\mathrm{K}_{3}$ increase with the deflection increases, indicating that the large deformation of composites speeds up the opening of crack mouth.

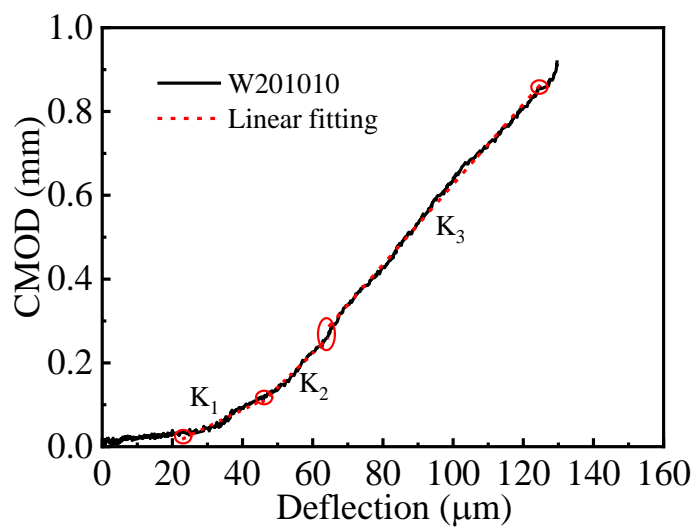

(a) W201010

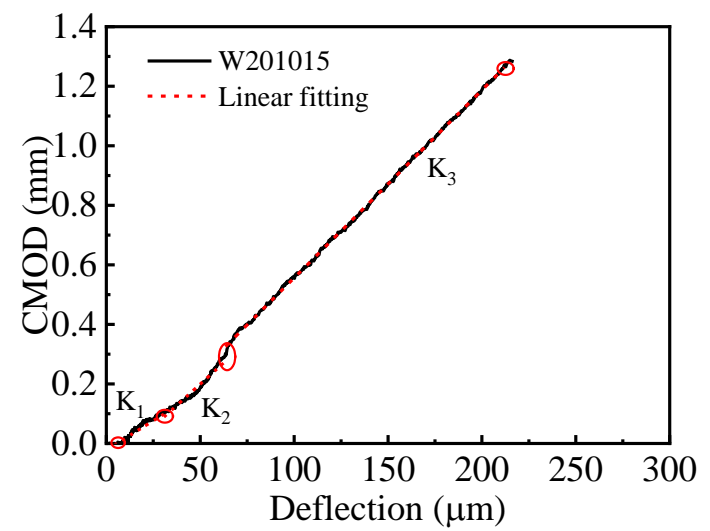

(b) W201015

Fig. $10 a_{0} / h=0.5$, the fitting relationship between $\delta$ and CMOD of SSW reinforced RPC

Table $7 a_{0} / h=0.5$, fitting equations of $\delta$ and CMOD for SSW reinforced RPC

\begin{tabular}{ccccc}
\hline Specimens & Fitting equation & $\mathrm{K}$ & Deflection range & $\mathrm{R}^{2}$ \\
\hline \multirow{3}{*}{ W201010 } & $\mathrm{CMOD}=0.00406 \delta-0.07464$ & $\mathrm{~K}_{1}=0.00406$ & $(22.78,46.06]$ & 0.89590 \\
& $\mathrm{CMOD}=0.00816 \delta-0.26639$ & $\mathrm{~K}_{2}=0.00816$ & $(46.06,64.53]$ & 0.98663 \\
& $\mathrm{CMOD}=0.00957 \delta-0.33150$ & $\mathrm{~K}_{3}=0.00957$ & $(64.53,128.32]$ & 0.99736 \\
\hline \multirow{3}{*}{ W201015 } & $\mathrm{CMOD}=0.00394 \delta-0.02217$ & $\mathrm{~K}_{1}=0.00394$ & $(0,30.66]$ & 0.83047 \\
& $\mathrm{CMOD}=0.00572 \delta-0.08669$ & $\mathrm{~K}_{2}=0.00572$ & $(30.66,63.44]$ & 0.95175 \\
& $\mathrm{CMOD}=0.00631 \delta-0.07482$ & $\mathrm{~K}_{3}=0.00631$ & $(63.44,216.90]$ & 0.99959 \\
\hline
\end{tabular}


Based on the three-stage linear fitting relationship, the characteristic values of $C M O D$ corresponding to different deflections are displayed in Table 8. The energy absorption and equivalent flexural strength of SSW reinforced RPC calculated by $C M O D$ characteristic values are shown in Table 9. It can be found from Table 9 that the energy absorption $D_{c r}, D_{1 f}$ and $D_{2 f}$ of RPC reinforced with $1.5 \%$ SSWs are $40.3 \%$, $149.4 \%$ and $22.5 \%$ higher than that of RPC reinforced with $1.0 \%$ SSWs. At the stage of crack stable propagation, the toughening efficiency of SSW is more easily affected by content. The equivalent flexural strength $f_{\text {eq1 }}$, and $f_{\text {eq2 }}$ of SSW reinforced RPC are increased by $83.8 \%$ and $34.0 \%$ due to the SSW content increases.

The relative errors between equivalent flexural strength obtained by load-deflection curves and that obtained by load-CMOD curves are listed in Table 10. Table 10 indicates that the relative error for RPC reinforced with $1.0 \% \mathrm{SSW}$ is smaller than $9.1 \%$, while that for RPC reinforced with $1.5 \%$ SSWs can reach $32.3 \%$. However, the variation of equivalent flexural strength with SSW content calculated based on load-deflection curves is similar to that calculated based on load-CMOD curves, showing that the flexural toughness of SSW reinforced RPC can be characterized by the limitation capacity of composites on the opening of crack mouth.

Table $8 a_{0} / h=0.5$, characteristic values of CMOD corresponding to different $\delta$

\begin{tabular}{ccccccc}
\hline \multirow{2}{*}{ Specimens } & $\begin{array}{c}\delta_{u} \\
/ \mu \mathrm{m}\end{array}$ & $\begin{array}{c}C M O D_{u} \\
/ \mathrm{mm}\end{array}$ & $\begin{array}{c}\delta_{u 1} \\
/ \mu \mathrm{m}\end{array}$ & $\begin{array}{c}C M O D_{1} \\
/ \mathrm{mm}\end{array}$ & $\begin{array}{c}\delta_{u 2} \\
/ \mu \mathrm{m}\end{array}$ & $\begin{array}{c}C M O D_{2} \\
/ \mathrm{mm}\end{array}$ \\
\hline $\mathrm{W} 201010$ & 33.6 & 0.0616 & 49.0 & 0.1334 & 125.1 & 0.8656 \\
$\mathrm{~W} 201015$ & 23.7 & 0.0711 & 47.3 & 0.1838 & 136.3 & 0.7854 \\
\hline
\end{tabular}

Table $9 a_{0} / h=0.5$, energy absorption and equivalent flexural strength of SSW reinforced RPC based on CMOD

\begin{tabular}{cccccc}
\hline Specimens & $\begin{array}{c}D_{\text {cr }} \\
/ \mathrm{kN} \cdot \mathrm{mm}\end{array}$ & $\begin{array}{c}D_{l f} \\
/ \mathrm{kN} \cdot \mathrm{mm}\end{array}$ & $\begin{array}{c}D_{2 f} \\
/ \mathrm{kN} \cdot \mathrm{mm}\end{array}$ & $\begin{array}{c}f_{\text {eql }} \\
/ \mathrm{MPa}\end{array}$ & $\begin{array}{c}f_{\text {eq2 }} \\
/ \mathrm{MPa}\end{array}$ \\
\hline $\mathrm{W} 201010$ & 0.0313 & 0.1118 & 0.4600 & 10.5 & 5.0 \\
$\mathrm{~W} 201015$ & 0.0439 & 0.2788 & 0.5635 & 19.3 & 6.7 \\
\hline
\end{tabular}


Table $10 a_{0} / h=0.5$, relative error of equivalent flexural strength

\begin{tabular}{ccccccc}
\hline \multirow{2}{*}{ Specimens } & \multicolumn{2}{c}{ Based on $\delta$} & \multicolumn{2}{c}{ Based on CMOD } & \multicolumn{2}{c}{ Relative error } \\
& $f_{\text {eq } 1} / \mathrm{MPa}$ & $f_{\text {eq }} / \mathrm{MPa}$ & $f_{\text {eql }} / \mathrm{MPa}$ & $f_{\text {eq2 }} / \mathrm{MPa}$ & $\Delta f_{\text {eq } 1}$ & $\Delta f_{\text {eq } 2}$ \\
\hline $\mathrm{W} 201010$ & 10.7 & 5.5 & 10.5 & 5.0 & $1.9 \%$ & $9.1 \%$ \\
$\mathrm{~W} 201015$ & 15.1 & 9.9 & 19.3 & 6.7 & $27.8 \%$ & $32.3 \%$ \\
\hline
\end{tabular}

\subsection{Four-point bending plate test results}

The load-deflection and load-displacement curves of plates for SSW reinforced RPC are plotted in Fig. 11. As shown in Fig. 11, there are three stages on load-deflection/displacement curves of plates, including elastic ascending stage, non-linear ascending stage and descending stage. The increase of SSW content leads to the prolongation of elastic ascending stage, more obvious non-linear ascending stage and more slow descending stage. The appearance of non-linear ascending stage can be attributed to the inhibiting effect of SSW on the crack initiation and propagation. When the load drops by more than $80 \%$ of peak load, the load-deflection/displacement curves of RPC reinforced with $1.5 \%$ SSWs decline slowly. And then, the load-deflection/displacement curves step into sharp descending stage due to rupture of SSWs. With the appearance of macro cracks, the tensile stress is transferred to SSWs. The propagation of macro cracks is hindered by the bridging effect of SSWs. The existence of sharp descending stage on load-deflection/ displacement curves represents the rupture of SSWs.

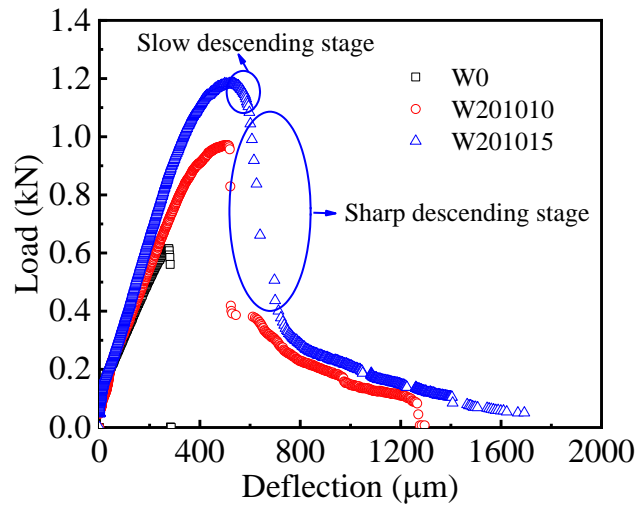

(a) Load-deflection curves

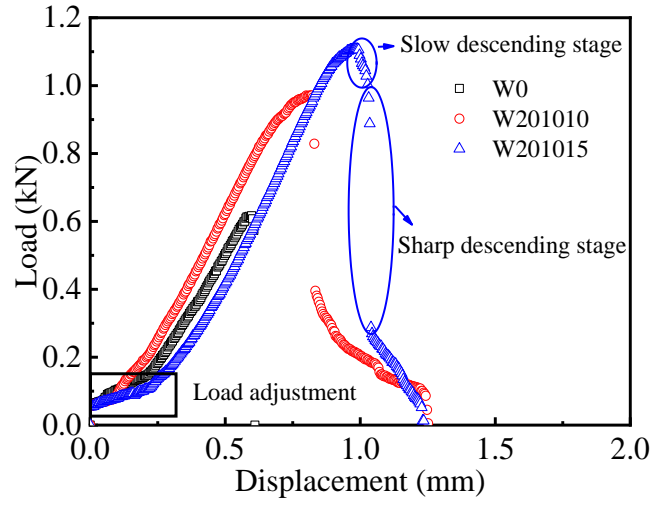

(b) Load-displacement curves 
Fig. 11 Load-deflection and load-displacement curves of plates for SSW reinforced RPC

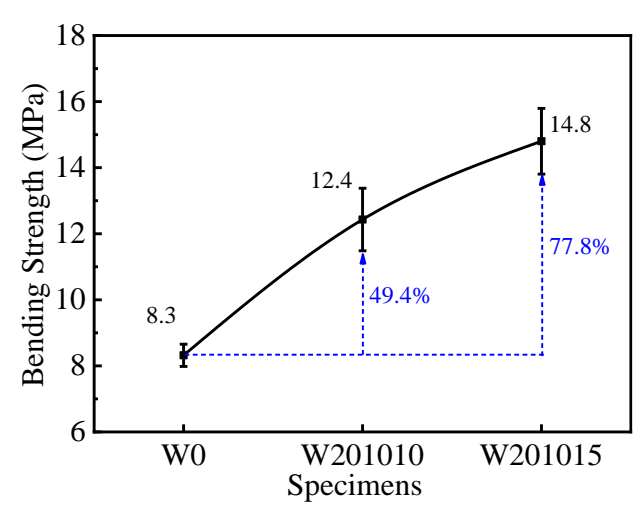

(a) Bending strength

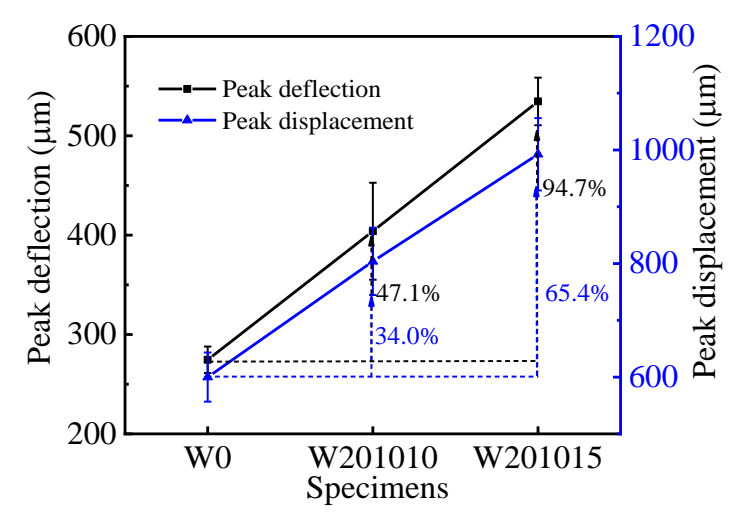

(b) Peak deflection/displacement

Fig. 12 Bending strength, peak deflection and displacement of plates for SSW reinforced RPC

The bending strength, peak deflection and displacement of plates for SSW reinforced RPC are demonstrated in Fig 12. Fig. 12(a) shows that the bending strength of RPC reinforced with $1 \%$ and $1.5 \%$ SSWs is enhanced by $49.4 \%$ and $77.8 \%$, respectively compared to the control RPC. Fig. 12(b) displays that the incorporation of $1 \%$ and $1.5 \%$ SSWs leads to $47.1 \%$ and $94.7 \%$ increase for peak deflection of RPC as well as $4.0 \%$ and $65.4 \%$ increase for peak displacement. The test results indicate that the inhibiting effect of SSWs on the initiation and propagation of cracks increases with the increase of SSW content. The peak displacement of RPC reinforced with $0 \%, 1 \%$ and $1.5 \%$ SSWs is $118.5 \%, 103.9 \%$ and $85.7 \%$ higher than the peak deflection. This means that the effect of testing machine rigidity on peak deformation of SSW reinforced RPC is reduced by the increasing SSW content.

The calculation results of flexural toughness for plates of SSW reinforced RPC are shown in Fig. 13. It is clear from Fig. 13(a) that compared with RPC without SSW, the peak flexural toughness of RPC reinforced with $1 \%$ and $1.5 \%$ SSWs based on 
load-deflection curves is enhanced by $137.2 \%$ and $250.3 \%$, and that based on load-displacement curves is increased by $85.6 \%$ and $169.5 \%$, respectively. The peak flexural toughness of RPC reinforced with $0 \%, 1 \%$ and $1.5 \%$ SSWs calculated according to load-displacement curves is $103.6 \%, 59.3 \%$ and $56.6 \%$ higher than that calculated on the basis of load-deflection curves. The variation of peak flexural toughness with SSW content is similar to that of peak deflection and displacement. Fig. 13(b) demonstrates that when the load-deflection curves are employed, the increments of limit flexural toughness for RPC with $1 \%$ and $1.5 \%$ SSWs are $108.8 \%$ and $201.9 \%$, respectively compared to control RPC. Meanwhile, the increases of $227.2 \%$ and $413.6 \%$ are obtained for limit flexural toughness of composites when the load-displacement curves are used. The limit flexural toughness of RPC reinforced with $0 \%, 1.0 \%$ and $1.5 \%$ SSWs calculated by load-displacement curves is $98.6 \%$, $26.4 \%$ and $16.4 \%$ higher than that calculated by load-deflection curves. The deformation ability enhancement of RPC caused by SSWs prevents the test values of limit flexural toughness from suffering the effect of the testing machine. The change rule of flexural toughness for RPC plates with the increase of SSW content is the same whether the load-deflection curves or the load-displacement curves are employed.

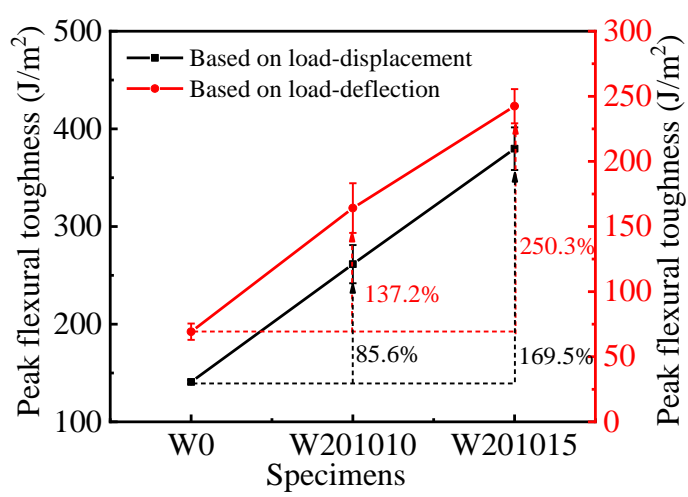

(a) Peak flexural toughness

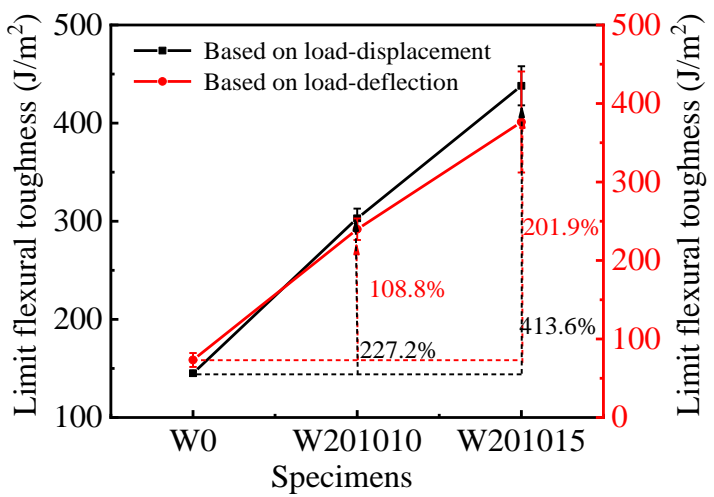

(b) Limit flexural toughness

Fig. 13 Flexural toughness of plates for SSW reinforced RPC 
The ratios of peak flexural toughness to limit flexural toughness for plates of RPC reinforced with $0 \%, 1 \%$ and $1.5 \%$ SSWs are $94.4 \%, 68.4 \%$ and $64.4 \%$ respectively on the basis of load-deflection curves, and the ratios are $97.1 \%, 86.3 \%$ and $86.7 \%$ according to load-displacement curves, showing improvement of toughness. Hence, the experimental results indicate that the toughening effect of SSW on RPC increases with the increasing SSW content. After the formation of macro cracks, the bridging and rupture of SSWs are the main source of toughness.

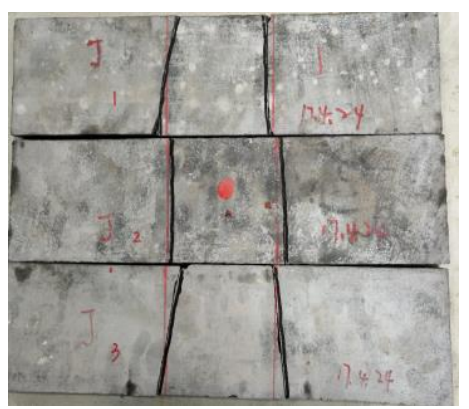

(a) W0

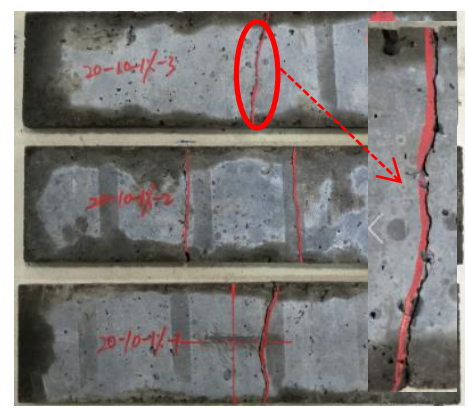

(b) W201010

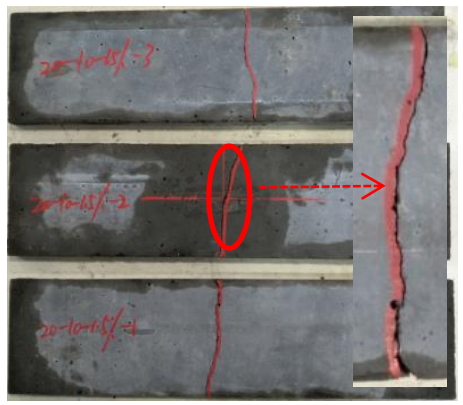

(c) W201015

Fig. 14 Cracking patterns of plates for SSW reinforced RPC

The cracking patterns of plates for SSW reinforced RPC are exhibited in Fig. 14. Fig. 14(a) shows that there are two stress concentration cracks on load points for failure plates of RPC without SSW. Fig. 14(b) manifests that an oblique penetrating crack between two load points or two stress concentration cracks on the load points appears on the failure plates of RPC reinforced with 1\% SSWs. Fig. 14(c) displays that there is a typical tensile penetrating crack at the mid-span of plates for RPC reinforced with $1.5 \%$ SSWs. The tensile stress caused by mid-span bending moment plays a dominate role in the loading process, and the generation and propagation of tensile cracks are inhibited by SSWs. Hence, the tensile cracks are tortuous and the crack path is prolonged.

\section{Calculation model for flexural toughness of SSW reinforced RPC}


The composite material theory is used to calculate the flexural toughness of SSW reinforced RPC in this section. The calculation basis of the composite material theory is mixing law, i.e., the properties of composite material are equivalent to the additive values of the properties of each component multiplied by the corresponding volume fraction. It is assumed that the properties of each component in composite material are independent of each other. Therefore, the composite material theory applies to fiber reinforced cementitious composite with fiber volume fraction not more than $2 \%$ [29]. The maximum volume fraction of SSW in this paper is $1.5 \%$, therefore, the flexural toughness of SSW reinforced RPC can be analyzed by the composite material theory. However, the following factors must be taken into account in calculating the flexural toughness of disorderly discontinuous SSW reinforced RPC using mixing law.

1) The efficiency of SSW in the direction of tensile stress is reduced because of the three-dimensional disordered characteristic of SSW in RPC. Therefore, the orientation coefficient $\eta_{0}$ should be introduced into the mixing law calculation equation.

2) Due to the discontinuous characteristic of SSW, the SSW would slide with the crack opening of RPC matrix. Hence, the length coefficient $\eta_{l}$ should be considered on the basis of SSW length range in the calculating process of flexural toughness.

When fibers are uniformly distributed in all directions in the plane and space, the orientation coefficient $\eta_{0}$ of fiber is equal to 0.375 and 0.2 , respectively [30]. For three-dimensional disorderly distributed SSWs, the orientation coefficient can be obtained by the following calculation. For a single SSW in RPC, the value of orientation coefficient is affected by the distance between SSW and specimen edge. Assuming that the distance between the geometric center line of SSW and specimen edge is $\alpha l_{f}$ ( $l_{f}$ is the length of SSW, $0<\alpha<1$ ), the relationship between $\alpha$ and 
orientation coefficient $\eta_{0}$ is shown in Fig. 15 [31]. The mold constrains the free rotation of SSW in RPC as the distance between SSW and specimen edge is less than the length of SSW, resulting in the boundary wall effect. At this point, the SSWs are distributed on the surface of specimen in parallel and maybe concentrated in the region near the side wall of specimen. When the distance between SSW and specimen edge is larger than the length of SSW, SSWs are assumed to uniformly distribute in RPC. Hence, when specimen section width $(t)$ satisfies the condition of $t>2 l_{f}$, the average value of orientation coefficient $\overline{\eta_{0}}$ for all SSWs in RPC has the following relation with specimen section width and SSW length, as shown in Equation (7) [31].

$$
\overline{\eta_{0}}=\left(2 \int_{0}^{l_{f}} \eta_{0} d x+\frac{3}{8}\left(t-2 l_{f}\right)\right) / t
$$

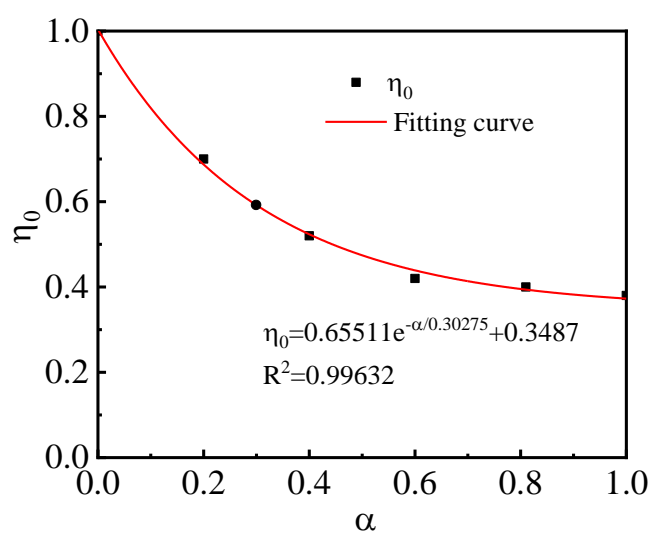

Fig .15 Boundary wall effect on SSW orientation coefficient [31]

It can be inferred from Fig. 15 and Equation (7) that the average value of SSW orientation coefficient $\overline{\eta_{0}}$ is 0.4574 and 0.4080 for beams and plates, respectively, studied in this paper. The results are similar to that of fiber orientation coefficient $\eta_{0}=0.407$ used by Romualdi and Mandel [32] when they proposed fiber spacing theory in 1964. 
After the formation of macro cracks in the specimens of SSW reinforced RPC, the load is transferred to SSWs until they are pulled-out from RPC matrix or rupture. The tensile strength of composites can be calculated on the basis of the following Equation (8) [29].

$$
\sigma_{f c}^{u}=2 \eta_{l} \eta_{0} \frac{l_{f}}{d_{f}} \tau V_{f}
$$

where the subscript $f$ represents SSW; $\sigma_{f c}^{u}$ is the tensile strength of SSW reinforced RPC (fiber reinforced concrete); $l_{f}$ is the length of SSW; $d_{f}$ is the diameter of SSW; $\tau$ is the average interfacial bonding strength between SSW and RPC matrix; $V_{f}$ is the volume fraction of SSW.

The correlation between flexural strength and tensile strength of fiber reinforced concrete is expressed by the following Equation (9) [33].

$$
\sigma_{f c}^{b}=2.44 \sigma_{f c}^{u}
$$

where $\sigma_{f c}^{b}$ and $\sigma_{f c}^{u}$ are the flexural strength and tensile strength of fiber reinforced concrete, respectively. Equation (9) can also be used to describe the relationship between flexural strength and tensile strength of SSW reinforced RPC.

Whether the SSWs are pulled-out or rupture in failure RPC specimens is closely related to the length of SSW. The relationship between the tensile stress undertaken by SSWs and the length of SSW are plotted in Fig. 16 [34]. Fig. 16 illustrates that: (1) if the length of SSW is smaller than the critical length $\left(l_{f}<l_{f}^{\text {crit }}\right)$, the SSW is pulled out from RPC matrix when composites fail; (2) if the length of SSW is equal to the critical length $\left(l_{f}=l_{f}^{\text {crit }}\right)$, the SSW rupture as the cracks appear in the middle position of SSW, otherwise the SSW is pulled out from the shorter embedded side; (3) 
if the length of SSW is larger than the critical length $\left(l_{f}>l_{f}^{\text {crit }}\right)$, the SSW rupture when composites fail.

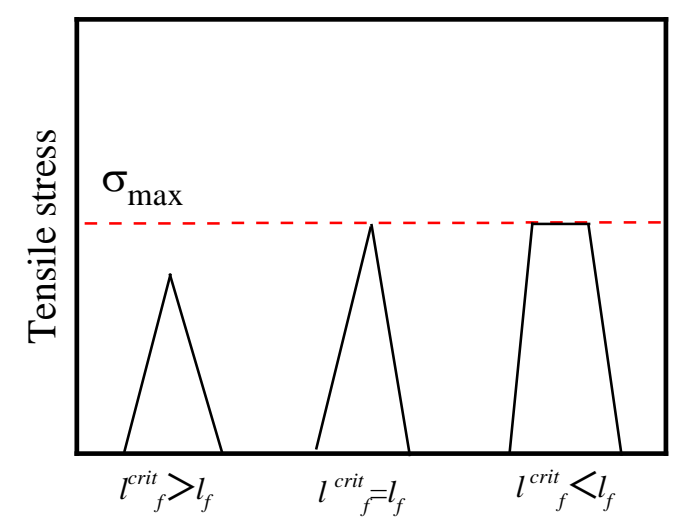

Fig. 16 Relationship between tensile stress and length of SSW [34]

In case of SSW rupture at the middle position, the following Equation (10) can be established.

$$
\pi d_{f} \frac{l_{f}^{c r i t}}{2} \tau=\frac{\pi}{4} d_{f}^{2} \sigma_{f}^{u}
$$

where $l_{f}^{\text {crit }}$ is the critical length of SSW; other symbols have the same meaning as Equations (8).

Thus, the critical length of SSW can be obtained by the following Equation (11).

$$
l_{f}^{c r i t}=\frac{d_{f} \sigma_{f}^{u}}{2 \tau}
$$

Furthermore, the interfacial bonding strength between RPC matrix and SSW can be obtained on the basis of Equation (8), as shown in Equation (12).

$$
\tau=\frac{\sigma_{f c}^{u} d_{f}}{2 \eta_{l} \eta_{o} l_{f} v_{f}}
$$


The length coefficient $\eta_{l}$ of SSW can be expressed as the following Equations (13) and (14), when the length of SSW satisfies the conditions of $l_{f} \leq l_{f}^{\text {crit }}$ and $l_{f}>l_{f}^{\text {crit }}$, respectively.

$$
\begin{array}{ll}
\eta_{l}=\frac{l_{f}}{2 l_{f}^{\text {crit }}} & l_{f} \leq l_{f}^{\text {crit }} \\
\eta_{l}=1-\frac{l_{f}^{\text {crit }}}{2 l_{f}} & l_{f}>l_{f}^{\text {crit }}
\end{array}
$$

Combing Equations (11), (12) and (13), the critical length of SSW can be calculated by the following Equation (15) when $l_{f} \leq l_{f}^{\text {crit }}$.

$$
l_{f}^{c r i t}=\frac{l_{f} \sqrt{\sigma_{f}^{u} \eta_{o} V_{f}}}{\sqrt{2 \sigma_{f c}^{b} / 2.44}} \quad \quad l_{f} \leq l_{f}^{c r i t}
$$

When $l_{f}>l_{f}^{\text {crit }}$, the critical length of SSW can be obtained by Iterative Equation (16) on the basis of (11), (12) and (14).

$$
l_{f}^{c r i t}=\frac{2 \eta_{0} V_{f} \sigma_{f}^{u} l_{f}}{2 \sigma_{f c}^{u}+\eta_{0} V_{f} \sigma_{f}^{u}} \quad l_{f}>l_{f}^{c r i t}
$$

The numbers of SSW per unit volume of composites, $N$, can be calculated from the following Equation (17).

$$
N=\frac{V_{f}}{A_{f} l_{f}}
$$

where $A_{f}$ is the cross-sectional area of SSW.

When the length of SSW satisfies the condition of $l_{f}>l_{f}^{\text {crit }}$, the average work $\bar{W}_{t}$ consumed by a single SSW can be calculated by the following Equation (18) [35, 36]. 


$$
\bar{W}_{t}=\frac{1}{24} \pi d_{f} \tau \frac{\left(l_{f}^{c r i t}\right)^{3}}{l_{f}}
$$

Hence, the increment value of flexural toughness $W_{t}^{\prime}$ can be obtained by multiplying the consumption work of a single SSW $\bar{W}_{t}$ and the numbers $N$ of SSW per unit volume of composites, as exhibited in Equation (19).

$$
W_{t}^{\prime}=N \frac{1}{24} \pi d_{f} \tau \frac{\left(l_{f}^{\text {crit }}\right)^{3}}{l_{f}}
$$

It should be noted that parts of beams of SSW reinforced RPC are not completely disconnected when failure happens. This means that not all SSWs contribute to the crack inhibition work of RPC beams. The parameter of crack-height ratio $(\beta)$ is introduced to calculate the number efficiency of $\mathrm{SSW}$. The value of $\beta$ is the ratio of crack length to height of specimen. The crack length is obtained by measuring on failure beams, and the average value of crack length on three beams is determined as the final value. In addition, the value of $\beta$ is 1.0 for beams and plates completely disconnected as failure occurs. For notched beams, the crack length-depth ratio $\left(a_{0} / h\right)$ should be considered in the theoretical equation.

Then, the increment value of flexural toughness $W_{t}$ for SSW reinforced RPC is calculated on the basis of the following Equation (20).

$$
W_{t}=\left(1-a_{0} h\right) \beta N \frac{1}{24} \pi d_{f} \tau \frac{\left(l_{f}^{c r i t}\right)^{3}}{l_{f}}
$$

The relative error between the theoretical $W_{t}$ and experimental $W_{e}$ increment values of flexural toughness for SSW reinforced RPC, $\square$, can be obtained by Equation (21). 


$$
\Delta=\frac{\left|W_{t}-W_{e}\right|}{W_{e}} \times 100 \%
$$

The theoretical parameters and relative error of flexural toughness for unnotched beams under four-point bending load, notched beams under three-point bending load and plates under four-point bending load of SSW reinforced RPC are listed in Tables 11, 12 and 13, respectively. Tables 11, 12 and 13 illustrate that the length of SSW is larger than the critical length. Hence, the SSWs rupture when failure happens. Table 11 shows that the relative error for unnotched beams between the experimental increment values of flexural toughness obtained by load-displacement curves and the theoretical increment values is smaller than $5 \%$, and that between the experimental increment values obtained by load-deflection curves and the theoretical increment values is no more than $12.9 \%$. Table 12 displays that the maximum error for notched beams between the theoretical and experimental increment values of flexural toughness is $14.0 \%$. Meanwhile, the relative error for plates of composites is less than $10.5 \%$, as demonstrated in Table 13. Therefore, it can be concluded that the calculation model of Equation (20) for flexural toughness can accurately describe the toughening effect of SSW on RPC beams and plates.

Table 11 Theoretical parameters and relative error of flexural toughness for SSW reinforced RPC unnotched beams under four-point bending load

\begin{tabular}{ccc}
\hline Composites & W201010 & W201015 \\
\hline Numbers of SSW, $1 / \mathrm{mm}^{3}$ & 3.2 & 4.8 \\
Critical length of SSW, mm & 4.769 & 5.621 \\
Interfacial bonding strength, MPa & 1.636 & 1.388 \\
Length coefficient of SSW, $\eta_{l}$ & 0.762 & 0.719 \\
$\quad$ Crack-height ratio, $\beta$ & 0.75 & 0.80 \\
Theoretical increment value $W_{t}$, & 111.44 & 247.69 \\
$\mathrm{~J} / \mathrm{m}^{2}$ & & \\
Experimental value $W_{e}$ & 107.13 & 260.75 \\
(load-displacement), $\mathrm{J} / \mathrm{m}^{2}$ & 4.0 & 5.0 \\
$\Delta / \%$ & 127.89 & 266.99 \\
Experimental value $W_{e}$ & &
\end{tabular}


(load-deflection), $\mathrm{J} / \mathrm{m}^{2}$

$\Delta / \%$

12.9

7.2

Table 12 Theoretical parameters and relative error of flexural toughness for SSW reinforced RPC notched beams under three-point bending load

\begin{tabular}{|c|c|c|c|}
\hline$a_{0} / h$ & & W201010 & W201015 \\
\hline \multirow{9}{*}{0.25} & Numbers of SSW, $1 / \mathrm{mm}^{3}$ & 3.2 & 4.8 \\
\hline & Critical length of SSW, mm & 5.7 & 6.4 \\
\hline & Interfacial bonding strength, MPa & 0.731 & 0.826 \\
\hline & Length coefficient of SSW, $\eta_{l}$ & 0.715 & 0.678 \\
\hline & Crack-height ratio, $\beta$ & 1.0 & 0.75 \\
\hline & $a_{0} / h$ & 0.25 & 0.25 \\
\hline & Theoretical increment value $W_{t}, \mathrm{~J} / \mathrm{m}^{2}$ & 85.01 & 155.87 \\
\hline & Experimental value $W_{e}$ (load-deflection), $\left(\bar{D}-D_{c r}\right) \mathrm{J} / \mathrm{m}^{2}$ & 74.90 & 141.10 \\
\hline & $\Delta / \%$ & 13.6 & 10.5 \\
\hline \multirow{9}{*}{0.5} & Numbers of SSW, $1 / \mathrm{mm}^{3}$ & 3.2 & 4.8 \\
\hline & Critical length of SSW, mm & 5.7 & 7.3 \\
\hline & Interfacial bonding strength, $\mathrm{MPa}$ & 0.731 & 0.931 \\
\hline & Length coefficient of SSW, $\eta_{l}$ & 0.715 & 0.637 \\
\hline & Crack-height ratio, $\beta$ & 1.0 & 0.90 \\
\hline & $a_{0} / h$ & 0.5 & 0.5 \\
\hline & Theoretical increment value $W_{t}, \mathrm{~J} / \mathrm{m}^{2}$ & 56.68 & 201.35 \\
\hline & Experimental value $W_{e}$ (load-deflection), $\left(\bar{D}-D_{c r}\right) \mathrm{J} / \mathrm{m}^{2}$ & 65.90 & 200.40 \\
\hline & $\Delta / \%$ & 14.0 & 0.5 \\
\hline
\end{tabular}

Table 13 Theoretical parameters and relative error of flexural toughness for SSW reinforced RPC plates under four-point bending load

\begin{tabular}{ccc}
\hline Composites & W201010 & W201015 \\
\hline Numbers of SSW, $1 / \mathrm{mm}^{3}$ & 3.2 & 4.8 \\
Critical length of SSW, mm & 4.775 & 5.665 \\
Interfacial bonding strength, MPa & 1.634 & 1.377 \\
Length coefficient of SSW, $\eta_{l}$ & 0.761 & 0.717 \\
$\quad$ Crack-height ratio, $\beta$ & 1.0 & 1.0 \\
Theoretical increment value $W_{t}$, & 148.96 & 314.43 \\
$\mathrm{~J} / \mathrm{m}^{2}$ & & \\
$\quad \begin{array}{c}\text { Experimental value } W_{e} \\
\text { (load-displacement), } \mathrm{J} / \mathrm{m}^{2}\end{array}$ & 157.89 & 292.97 \\
$\Delta / \%$ & 5.7 & 7.3 \\
$\begin{array}{c}\text { Experimental value } W_{e} \\
\text { (load-deflection), } \mathrm{J} / \mathrm{m}^{2}\end{array}$ & 166.52 & 303.13 \\
$\Delta / \%$ & 10.5 & 3.7
\end{tabular}




\section{Conclusions}

Unlike normal steel fiber, SSW can reduce the original flaw and enhance the compactness of RPC matrix because of its micron diameter and high specific surface area. The widely distributed SSW network in RPC can effectively transfer crack tip stresses and inhibit the initiation and propagation of cracks. These effects are beneficial for improving the flexural toughness of RPC. Therefore, the flexural toughness of SSW reinforced RPC beams and plates was investigated, and the calculation model was established according to the composite material theory.

The load versus deflection, displacement or CMOD curves of RPC beams and plates feature obvious non-linear ascending stage and slow descending stage under bending load due to the incorporation of SSW. The failure cracks of SSW reinforced RPC are tortuous and the failure sections are unsmooth. The bending strength of unnotched beams fabricated with RPC containing $1 \%$ and $1.5 \%$ SSWs is improved by $13.5 \%$ and $36.6 \%$ compared to that of control RPC. According to load-deflection curves, the peak and limit flexural toughness of unnotched RPC beams containing $1 \%$ and $1.5 \%$ SSWs are $43.0 \%, 111.7 \%$ and $50.0 \%, 146.5 \%$ higher than that of RPC without SSW, respectively. Similar variation trend is obtained when the load-displacement curves are employed. When the crack length/depth ratio is $0.25 / 0.5$, the flexural strength of notched beams fabricated with RPC reinforced with $1 \%$ and $1.5 \%$ SSWs is increased by $73.9 \% / 119.9 \%$ and $65.2 \% / 74.4 \%$, respectively, compared with corresponding beams without SSWs. The equivalent flexural strength of RPC reinforced with $1.5 \%$ SSWs is $80.0 \%$ higher than that of RPC reinforced with $1.0 \%$ SSWs. The load-CMOD curves can also be used to evaluate the flexural toughness of composites. The bending strength of RPC plates is enhanced by $49.4 \%$ and $77.8 \%$ due to the incorporation of $1 \%$ and $1.5 \%$ SSWs, respectively. On the basis 
of load-deflection curves, the addition of $1 \%$ and $1.5 \%$ SSWs leads to $137.2 \%$ and $250.3 \%$ increase for peak flexural toughness as well as $108.8 \%$ and $201.9 \%$ increase for limit flexural toughness. The similar variation of flexural toughness can be obtained for SSW reinforced RPC plates according to load-displacement curves. The relative error between the experimental increment values and theoretical values of flexural toughness is smaller than $14.0 \%$ for beams and plates under bending load, indicating the reliability of the proposed theoretical model and the toughening effect of SSW on RPC can be well described by the composite material theory.

The enhancement of RPC flexural toughness caused by SSWs broadens the engineering applications of concrete and improves the structure safety. In addition, the designability of toughening effect of SSW on RPC can provide theoretical basis for structural calculation.

\section{Acknowledgments}

The authors thank the funding supported from National Key Research and Development Program of China (2018YFC0705601) and China Postdoctoral Science Fundation (2019M651116).

\section{References}

[1] Jang S., Yun H. Combined effects of steel fiber and coarse aggregate size on the compressive and flexural toughness of high-strength concrete. Composite Structures. 2018,185: 203-211.

[2] Kim D. J., Park S. H., Ryu G. S., et al. Comparative flexural behavior of Hybrid Ultra High Performance Fiber Reinforced Concrete with different macro fibers. Construction and Building Materials. 2011,25(11): 4144-4155.

[3] Banthia N., Majdzadeh F., Wu J., et al. Fiber synergy in Hybrid Fiber Reinforced Concrete (HyFRC) in flexure and direct shear. Cement and Concrete Composites. 2014,48: 91-97. 
[4] Li X. L., Luo M., Wang J. Experimental research on flexural toughness of green high performance fiber reinforced cementitious composites. Materials Research Innovations. 2014,18(sup2): S2.

[5] Zhao X., He X. High-toughness and durability performance characterization of concrete reinforced with poly(vinyl alcohol) fibers. Materials Express. 2014,4(3): 247-252.

[6] Zhang L., Liu J., Liu J., et al. Effect of Steel Fiber on Flexural Toughness and Fracture Mechanics Behavior of Ultrahigh-Performance Concrete with Coarse Aggregate. Journal of Materials in Civil Engineering. 2018,30(12).

[7] Rashiddadash P., Ramezanianpour A. A., Mahdikhani M. Experimental investigation on flexural toughness of hybrid fiber reinforced concrete (HFRC) containing metakaolin and pumice. Construction and Building Materials. 2014,51: 313-320.

[8] Kim H., Kim G., Gucunski N., et al. Assessment of flexural toughness and impact resistance of bundle-type polyamide fiber-reinforced concrete. Composites Part B: Engineering. 2015,78: $431-446$.

[9] Yap S. P., Bu C. H., Alengaram U. J., et al. Flexural toughness characteristics of steelpolypropylene hybrid fibre-reinforced oil palm shell concrete. Materials and Design. 2014,57: $652-659$.

[10] Ding Y., Zhang Y., Thomas A. The investigation on strength and flexural toughness of fibre cocktail reinforced self-compacting high performance concrete. Construction and Building Materials. 2009,23(1): 448-452.

[11] Khan M. I., Abbas Y. M., Fares G. Review of high and ultrahigh performance cementitious composites incorporating various combinations of fibers and ultrafines. Journal of King Saud University - Engineering Sciences. 2017,29(4): 339-347.

[12] Sivakumar A., Santhanam M. Mechanical properties of high strength concrete reinforced with metallic and non-metallic fibres. Cement and Concrete Composites. 2007,29(8): 603-608.

[13] Ahmed S. F. U., Maalej M., Paramasivam P. Flexural responses of hybrid steel-polyethylene fiber reinforced cement composites containing high volume fly ash. Construction and Building Materials. 2007,21(5): 1088-1097. 
[14] Wang B., Han Y., Liu S. Effect of highly dispersed carbon nanotubes on the flexural toughness of cement-based composites. Construction and Building Materials. 2013,46: 8-12.

[15] Le H. V., Moon D., Kim D. J. Effects of ageing and storage conditions on the interfacial bond strength of steel fibers in mortars. Construction and Building Materials. 2018, 170: 129-141.

[16] Hwang J. P., Kim M., Ann K. Y. Porosity generation arising from steel fibre in concrete. Construction and Building Materials. 2015,94:433-436.

[17] Bentur A., Mindess S. Fibre Reinforced Cementitious Composites // Materials for Buildings and Structures, Volume 6. Wiley-VCH Verlag GmbH \& Co. KGaA, 2006.

[18] Han B., Dong S., Ou J., et al. Microstructure related mechanical behavior of short-cut super-fine stainless wire reinforced reactive powder concrete. Materials and Design. 2016,96: $16-26$.

[19] Dong S., Han B., Yu X., et al. Dynamic impact behavior and constitutive model of super-fine stainless wire reinforced reactive powder concrete. Construction and Building Materials. 2018,184: 602-616.

[20] Dong S., Han B., Yu X., et al. Constitutive model and reinforcing mechanisms of uniaxial compressive property for reactive powder concrete with super-fine stainless wire. Composites Part B: Engineering. 2019, 166: 298-309.

[21] Dong S., Han B., Ou J., et al. Electrically conductive behavior and mechanisms of short-cut super-fine stainless wire reinforced reactive powder concrete. Cement and Concrete Composites. 2016, 72: 48-65.

[22] Richard P., Cheyrezy M. Composition of reactive powder concretes. Cement Concrete Research. 1995, 25(7):1501-1511.

[23] ASTM C1609/C1609M-07.Standard test method for flexural performance of fiber-reinforced concrete (using beam with third-point loading).American Society of Testing and Materials. 2007:1-8.

[24] JSCE steel fiber reinforced concrete research subcommittee. Recommendation for design and construction of steel fiber reinforced concrete. Concrete library of JSCE No3. 1984,06.

[25] RILEM TC162-TDF: Test and Design Methdos for Steel Fibre Reinforced Concrete: bending Test, final Recommendation. Materials and Structures, 2002(35):579-582. 
[26] China engineering construction association standard: Standard test methods for fiber reinforced concrete (CECS 13-2009). China planning press, 2010, 02. (In Chinese)

[27] Banthia N, Trottier J F. Effects of curing temperature and early freezing on the pull-out behavior of steel fibers. Cement and Concrete Research, 1989, 19(3):400-410.

[28] Jenq Y. S., Shah S. P. A Fracture toughness criterion for concrete. Engineering Fracture Mechanics. 1985,21(5): 1055-1069.

[29] Shen R.X., Cui Q., Li Q. H. New type fiber reinforced cement-based composites. China building material industry press, 2004:49-85. (In Chinese)

[30] Krenchel H. Fiber Reinforcement. Copenhagen: Akademisk Forlay, 1964.

[31] Zhao Y. H., Xiong J. Boundary effect of two dimensional directional coefficient of steel fiber reinforced concrete. Engineering Mechanics. 1998(a02):337-341. (In Chinese)

[32] Romualdi J. P., Mandel J. A. Tensile strength of concrete affected by uniformly distributed and closely spaced short lengths of wire reinforcement. ACI Structural Journal, 1964,61(6):27-37. [33] Hannant D.J. Fiber Cements and Fiber Concretes. Chichester: John Wiley \& Sons, 1978

[34] Han B., Zhang L., Zhang C., et al. Reinforcement effect and mechanism of carbon fibers to mechanical and electrically conductive properties of cement-based materials. Construction and Building Materials, 2016,125:479-489.

[35] Kelly A.. Interface Effects and the Work of Fracture of a Fibrous Composite. Proceedings of the Royal Society A, 1970,319(1536):95-116.

[36] Pigott M. R.. Theoretical Estimation of Fracture Toughness of Fibrous Composites, Journal of Material Science, 1970, 5 (8): 669-675 